Florida International University

FIU Digital Commons

$10-29-2020$

\title{
Unifying Assessments of Sustainability and Resilience in Civil Infrastructure Systems: The Case of Masonry Structures
}

Samir J. Pandey

Florida International University, spand024@fiu.edu

Follow this and additional works at: https://digitalcommons.fiu.edu/etd

Part of the Civil Engineering Commons, and the Construction Engineering and Management Commons

\section{Recommended Citation}

Pandey, Samir J., "Unifying Assessments of Sustainability and Resilience in Civil Infrastructure Systems: The Case of Masonry Structures" (2020). FIU Electronic Theses and Dissertations. 4596.

https://digitalcommons.fiu.edu/etd/4596

This work is brought to you for free and open access by the University Graduate School at FIU Digital Commons. It has been accepted for inclusion in FIU Electronic Theses and Dissertations by an authorized administrator of FIU Digital Commons. For more information, please contact dcc@fiu.edu. 


\section{FLORIDA INTERNATIONAL UNIVERSITY}

Miami, Florida

UNIFYING ASSESSMENTS OF SUSTAINABILITY AND RESILIENCE IN CIVIL INFRASTRUCTURE SYSTEMS: THE CASE OF MASONRY STRUCTURES

A thesis submitted in partial fulfillment of

the requirements for the degree of

MASTER OF SCIENCE

in

CONSTRUCTION MANAGEMENT

by

Samir Jung Pandey

2020 
To: Dean John L. Volakis

College of Engineering and Computing

This thesis, written by Samir Jung Pandey, and entitled Unifying Assessments of Sustainability and Resilience in Civil Infrastructure Systems: The Case of Masonry Structures, having been approved in respect to style and intellectual content, is referred to you for judgment.

We have read this thesis and recommend that it be approved.

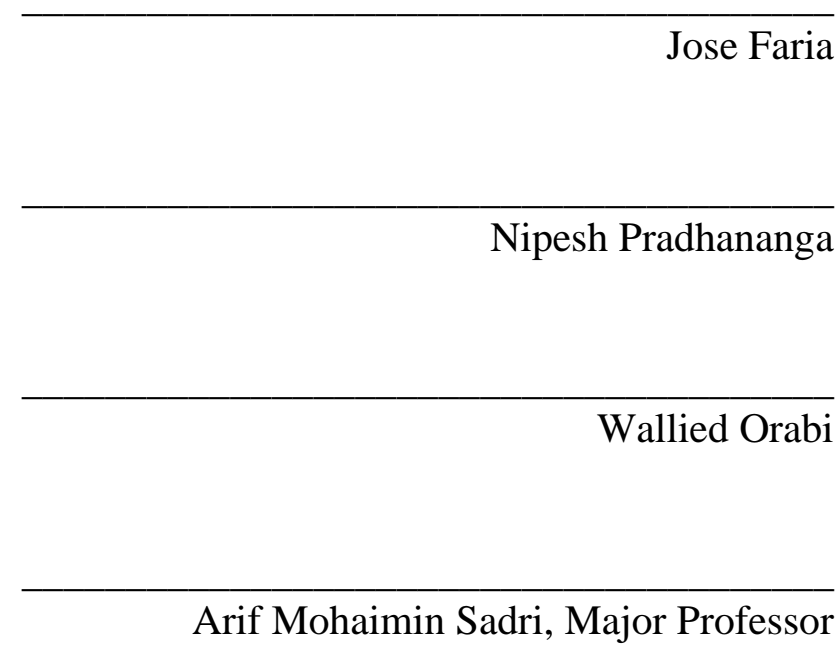

Date of Defense: October 29, 2020

The thesis of Samir Jung Pandey is approved.

Dean John L. Volakis College of Engineering and Computing

Andrés G. Gil Vice President for Research and Economic Development and Dean of the University Graduate School

Florida International University, 2020 
(C) Copyright 2020 by Samir Jung Pandey

All rights reserved. 


\section{DEDICATION}

I dedicate this thesis to my mother: Sumitra Kumari Thapa (Pandey), my father: Milan

Kumar Pandey and my brother: Sabin Jung Pandey. I would not have been where I am today without their unparalleled love and continuous support throughout my life. 


\section{ACKNOWLEDGMENTS}

Foremost, I would like to express my sincere gratitude to my advisor Dr. Arif Mohaimin Sadri for his patience, immense knowledge, continuous support and guidance throughout my graduate study. Without his expert supervision, this thesis would not have been possible.

Moreover, I am thankful to my committee members: Dr. Jose Faria, Dr. Nipesh Pradhananga and Dr. Wallied Orabi, for their invaluable comments and words of encouragement during my research and for finding time in their busy schedule for my dissertation.

I am forever indebted to my family for their unparalleled love and continuous motivation to be better; which made me who I am today. I sincerely want to thank all faculty members, my seniors and my friends of Moss Department of Construction Management, Florida International University for all their assistance. Last but not the least, I would like to thank Er. Pranit Malla for his significant help and Anupa Shrestha for her kind support during this research. 


\title{
ABSTRACT OF THE THESIS \\ UNIFYING ASSESSMENTS OF SUSTAINABILITY AND RESILIENCE IN CIVIL INFRASTRUCTURE SYSTEMS: THE CASE OF MASONRY STRUCTURES
}

\author{
by
}

\section{Samir Jung Pandey}

Florida International University, 2020

\section{Miami, Florida}

\section{Professor Arif Mohaimin Sadri, Major Professor}

Review of existing literature on the unification of sustainability and resilience showed the lack of a single effective framework that can unify the two, especially for building systems. Along this line of research, this study contributes a novel experimental framework to assess masonry structures and support a unified approach. This study performed structural analysis for resilience assessment and energy simulation for sustainability assessment. Based on the openings available in masonry walls, the study observed the changes in sustainability indicators (electricity consumption). Changes in resilience indicators (story drifts) were also observed. Results indicate that overall sustainability is compromised with additional openings in most cases. However, in most cases, electricity consumption for space heating decreases with additional openings. Results from resilience assessment show an increase in story drift of different floors with additional openings. Such results indicate that with additional openings, an unreinforced masonry building becomes more vulnerable to the damages from the earthquake lateral loads. Moreover, differential effects (positive/negative correlations) were observed when concurrent assessments were made on sustainability and resilience indicators. 
CHAPTER

PAGE

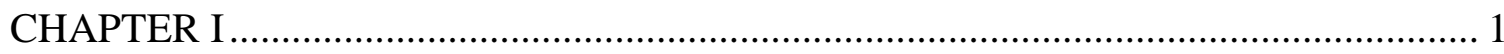

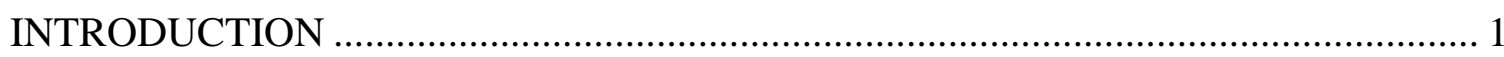

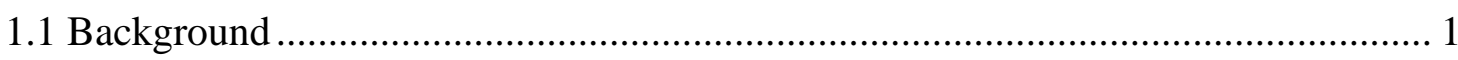

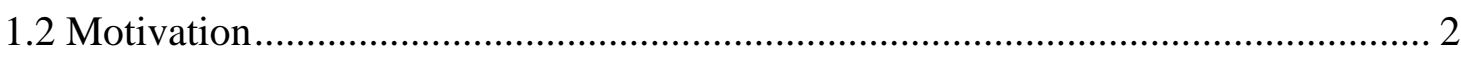

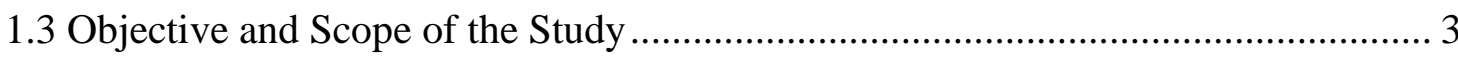

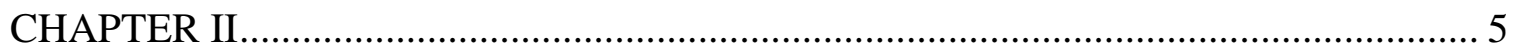

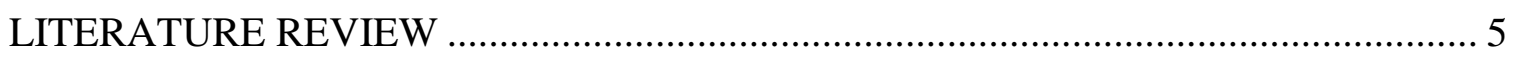

2.1 Studies on Sustainability and Difficulties in its Quantification.............................. 5

2.2 Studies on Resilience and Difficulties in its Quantification ..................................... 6

2.3 Studies on Unification of Sustainability and Resilience ........................................ 8

2.4 Knowledge Gap in the Literature..................................................................... 13

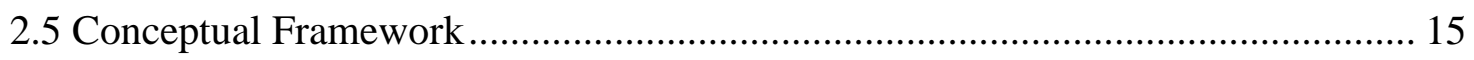

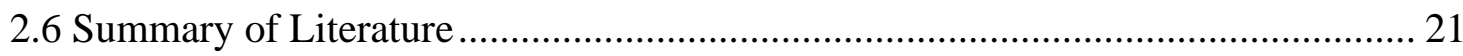

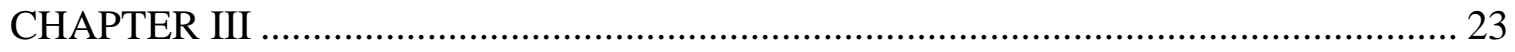

UNIFYING ASSESSMENTS FOR STRUCTURAL MASONRY ………………….... 23

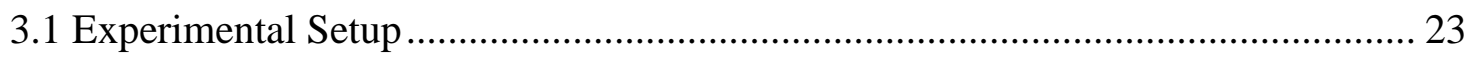

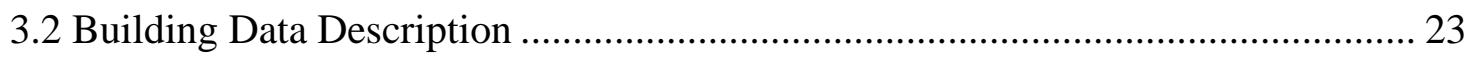

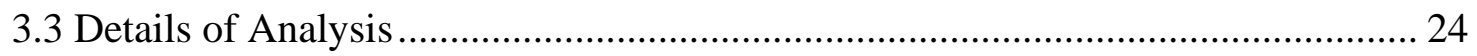

3.4 Modeling for Sustainability Assessment ......................................................... 25

3.5 Modeling for Resilience Assessment............................................................... 26

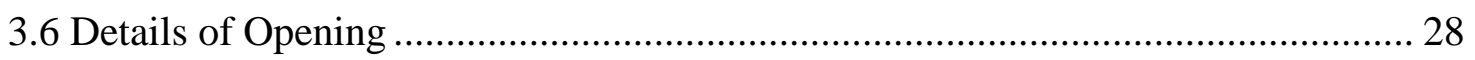

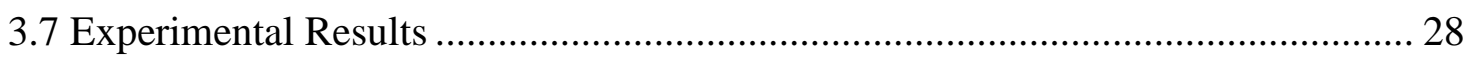

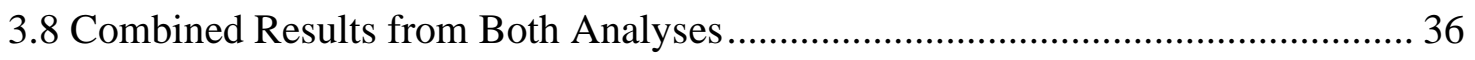

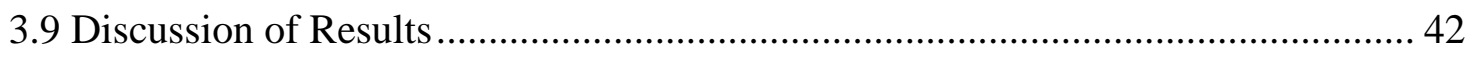

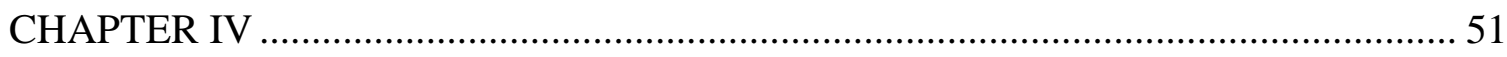

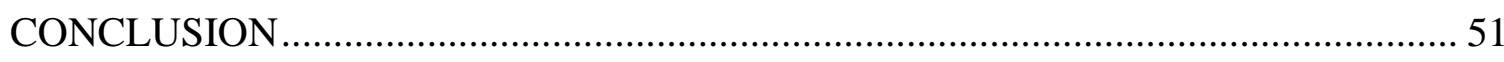

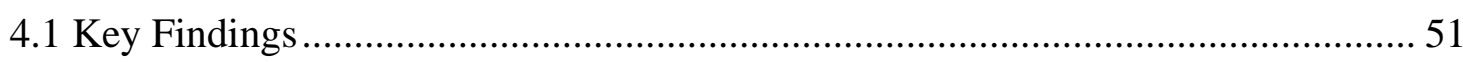

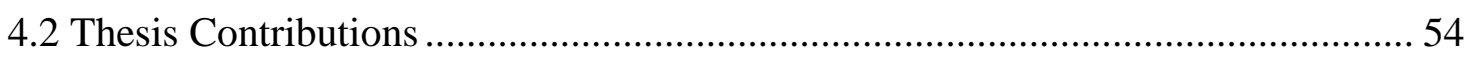


4.3 Limitations and Future Directions ...

REFERENCES . 


\section{LIST OF TABLES}

TABLE

PAGE

Table 1: Summary of studies on sustainability, resilience and their integration 21

Table 2: Details of Percentage Opening in Each Scenario ........................................ 28

Table 3: Sustainability Assessment Results for All Cases............................................. 29

Table 4: Resilience Assessment Results for All Cases .............................................. 33

Table 5: Changes (\%) in Sustainability and Resilience Indicators from Base Case........ 36

Table 6: Correlation between opening and each indicator from both analyses ............... 39

Table 7: Correlation between each sustainability and resilience indicator..................... 39

Table 8: Optimization results for different sets of constraints.................................. 47 


\section{LIST OF FIGURES}

FIGURE

PAGE

Figure 1: Resilience triangle [6]

Figure 2: Scope of sustainability factors for building and their connection to resilience [3]

Figure 3: Sustainability and resilience as separate efforts: approaches to sustainability and resilience can either be negatively correlated, uncorrelated, or positively correlated $[22]$

Figure 4: Various building design options considering opening 18

Figure 5: Critical factors affecting sustainability and resilience during different phases of a building life cycle

Figure 6: Four elevations and 3D view of original building model on eQUEST (base case scenario)

Figure 7: Walls of different case scenarios where openings are modified (with respect to base case) for sustainability assessment

Figure 8: Four elevations and 3D view of original building model on ETABS (base case scenario)

Figure 9: Walls of different case scenarios where openings are modified (with respect to base case) for resilience assessment

Figure 10: Graphical representation of the changes in sustainability indicators (a) for changes of openings only in the south wall, (b) for changes of openings in the remaining walls, (c) for simultaneous changes of opening in various walls (d) percentage change from base case for changes in the south wall (e) percentage change from base case for changes in other walls.

Figure 11: Graphical representation of the changes in resilience indicators (a) for changes of openings only in the south wall, (b) for changes of openings in the remaining walls, (c) for simultaneous changes of opening in various walls (d) percentage change from base case for changes in the south wall (e) percentage change from base case for changes in other walls 
Figure 12: Concurrent changes in sustainability and resilience indicators with respect

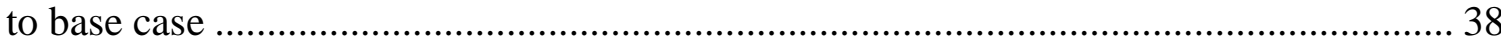

Figure 13: Graph of Opening vs $\mathrm{S}_{\mathrm{SH}}$ and Opening vs $\mathrm{RX}_{\mathrm{X}}{ }^{4}$ for Base Case to Case 6......... 49 


\section{CHAPTER I \\ INTRODUCTION}

\subsection{Background}

Sustainability has always been a topic of concern for infrastructure development projects during their expected lifespan: from initial planning, design, procurement and construction phase to operation, maintenance and demolition phase. With United Nations (UN) setting up Sustainable Development Goals (SDGs) to achieve within the year 2030, the sustainable development concept considers long-lasting development of any infrastructure and sustainable overall development of a nation [1]. In addition, the constant need for change in the built environment, due to increase in human population and the everincreasing consumption of various natural resources, has shown the importance of the concept of sustainable development. In the report "Our Common Future", The Brundtland Commission (1987) defined the concept of sustainability as "meeting the needs of the present without compromising the ability of future generations to meet their own needs" [2]. The report describes the sustainability as the type of development that simultaneously deals with the necessity of today's generation and necessity of the future generations without compromising or impacting them.

Additionally, to reduce the impact of natural disasters on infrastructure systems, we must focus on making our infrastructures more resilient. Resilience is generally defined as the capacity of predicting and dealing with disasters in a well-organized and convenient way [3]. So, alongside sustainability, the necessity of incorporating the concept of resilience during the infrastructure development process is also emerging rapidly. 
Construction of infrastructures around high-risk areas that face natural disasters is one of the main reasons why the concept of resilience has been drawing significant attention in the last few decades. Timmerman (1981) defined the concept of resilience as "the ability of human communities to withstand external shocks or perturbations to their infrastructure and to recover from such perturbations" [4]. In other words, resilience deals with the capacity of a system to deal with any disturbance and to efficiently recover from the damages caused by the disturbance.

\subsection{Motivation}

It is crucial for us to consider both sustainability and resilience while building an infrastructure. However, there is a need for developing a systematic methodology that analyzes both aspects together. The critical review of existing literature on unification of sustainability and resilience showed that, especially in context of buildings, there is a lack of an effective single framework for their integration [3, 5-7]. Such a framework can be used for the quantification of sustainability and resilience, making their integration possible during the design and construction phases of infrastructure. The development of such a framework for the reliable integration of sustainability and resilience is the major challenge for future researchers. The review of existing literature has also shown a knowledge gap regarding whether resilience and sustainability should be addressed in a unified or in a separate manner, so that the structure will ultimately become both resilient as well as sustainable $[5,8]$. The main problem for integration is that unifying these two concepts does not always result in the enhancement of an infrastructure because the same decision which is made based on sustainability assessment can weaken resilience of an infrastructure and vice versa [6]. 


\subsection{Objective and Scope of the Study}

This study reviewed existing literature to explore the concept of sustainability and resilience and their unification. Moreover, this study explored literature that specifically focused on their quantification and integration. This review also investigates how some of the relevant literature approached the systematic unification of sustainability and resilience. Within the scope of the research, this study explored answers to the following research questions: (a) is there a unified or single systematic methodology to quantify and integrate the concept of sustainability and resilience?; (b) can a unified/single framework combine both concepts?; (c) while designing and building an infrastructure, is it better if sustainability and resilience are considered separately or in a combined manner?.

Considering both concepts in the planning, design, operation and maintenance of civil infrastructure systems is important. Recent studies have shown the need to identify a unified framework that analyzes both aspects together [3, 5-7]. However, the empirical literature is inconclusive whether resilience and sustainability should be addressed in a unified or individual manner [5, 8]. Unifying these two concepts may not always result in the reinforcement of the infrastructure, since a decision based on sustainability assessment can undermine the resilience of the structure and vice versa [6]. Along these lines of research, this study contributes an experimental framework to assess masonry structures and support the unified approach.

In particular, in this study structural analysis was performed for resilience (i.e. robustness or structural integrity) assessment in masonry structures and simulations of energy consumption for sustainability. In this study, all windows and doors of a building 
are referred to as openings [9]. To simplify our approach, unreinforced masonry structure is selected. An unreinforced masonry building is defined as a "structure whose load-bearing system consists of an assemblage of masonry units generally made of stone, brick, or concrete blocks laid in a specific pattern and joined together with mortar" [10]. Based on the availability of openings in such buildings, this study analyzed the variations in energy consumption and structural performance against lateral load due to an earthquake. However, it is important to note that such variations observed in the case of unreinforced masonry structures may not hold in different scenarios, such as reinforced concrete frame structures. 


\section{CHAPTER II}

\section{LITERATURE REVIEW}

\subsection{Studies on Sustainability and Difficulties in its Quantification}

The triple bottom line (TBL) defines sustainability as an integration of three aspects: environmental, social and economic sustainability [11]. Some scholars simply define sustainability as longevity with less resource consumption and less impact (i.e. the longer a system can be sustained and operated, the more sustainable it becomes) [12]. Sustainability definitions can be vague and comprehensive in certain cases. For example, definitions include "an ethical concept that things should be better in the future than they are at present" [13] or "anything that ensures the wellbeing of societies and environments" [12]. Other sustainability definitions are narrower, such as "to maintain the status quo" [12].

Buildings play a major role as the main users of energy and material resources [14]. During the operating cycle, energy consumption has been commonly found to have the greatest impact among conventional buildings. Such an impact during the operating cycle of the building has drawn interest in design and construction of sustainable buildings [15, 16]. Consumption of energy can be associated to the design of heating, ventilation, and airconditioning (HVAC) systems, orientation of windows and openings, shading strategies, and performance of the building envelope systems [3]. Such consumption in the operation phase can be considerably decreased with a detailed energy analysis during the design and preconstruction phase, resulting in higher upfront costs but a decrease in total life-cycle costs [17]. Existing literature have shown that it is difficult to accurately quantify all dimensions and factors affecting the sustainability of an infrastructure $[5,18]$. The problem 
in sustainability quantification is mainly the social and ecological dimension [3, 5]. Both dimensions mostly deal with the factors that are qualitative in nature rather than quantitative $[3,5,6]$. Thus, social and ecological dimensions and factors impacting these dimensions (for example: human comfort that an infrastructure will provide, accurate quantification of environmental impact that an infrastructure will have, etc.) are currently one of the main difficulties surrounding accurate quantification of the sustainability of an infrastructure in existing literature [3, 5-7].

\subsection{Studies on Resilience and Difficulties in its Quantification}

Definition of resilience is different in many fields from psychology to civil engineering [19]. There are mainly two parts of resilience: considering the environmental conditions (i.e. ecological resilience) and considering the structural capacity (i.e. engineering resilience) [20]. Engineering resilience is defined as "bounce-back" resilience, which states that a system that can rapidly return to its normal undisturbed state after facing a disturbance is resilient [21]. On the other hand, ecological resilience is defined as systems having numerous balanced conditions or systems that can be changed respectively according to disturbance [22]. Engineering resilience pertains to mechanisms operating in single state of equilibrium, while environmental resilience pertains to mechanisms with various stable systems [20,23]. Another definition of resilience describes it as "the ability to prepare and plan for, absorb, recover from, and more successfully adapt to adverse events" [24].

Considering building structures, resilience is generally defined as the capacity of predicting and dealing with disasters in a well-organized and convenient way [3]. 
Resilience of buildings mainly focus on the time and effort required for gaining back its original functionality level [3]. Resilience has also been considered as an extension of available building codes and regulations (which usually focus on performance reliability, health and wellbeing of people), because it seeks to maximize disaster withstanding ability of buildings across a number of factors and not only on reducing the number of fatalities caused by various forms of disasters [25]. Many current changes in climate, such as the evolving patterns of storm events, global warming and rising sea levels, have pointed to the idea of making infrastructures not only resilient but also flexible to the environmental changes [26-28].

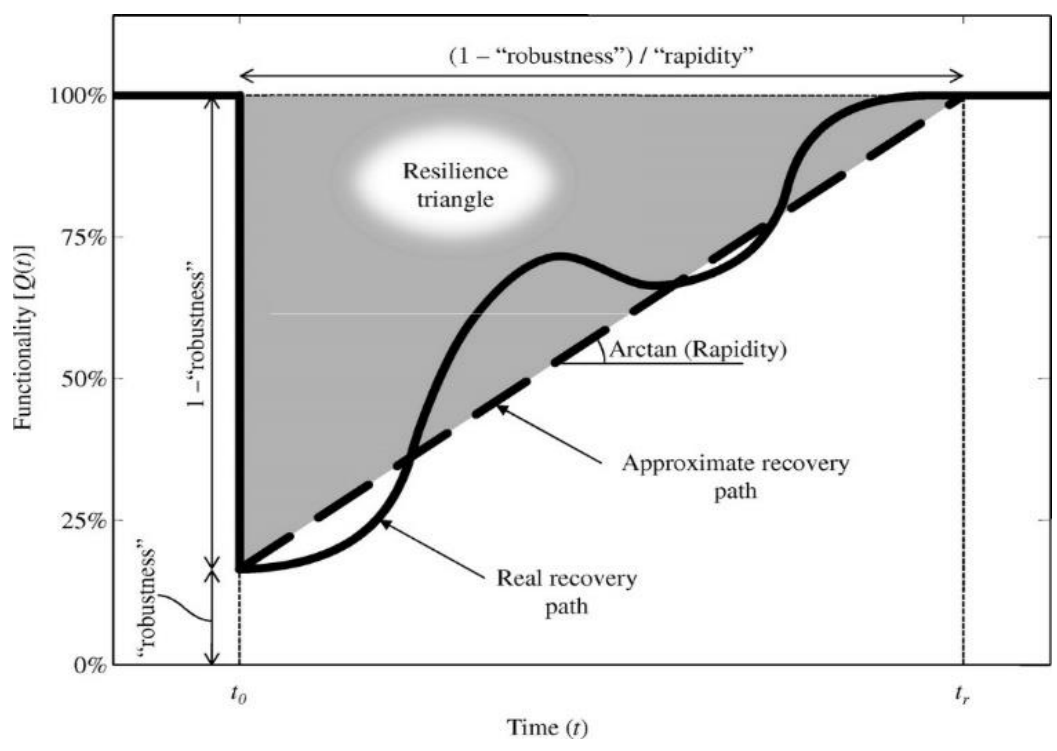

Figure 1: Resilience triangle [6]

The concept of 'resilience triangle' was introduced by Bruneau (2003) [29]. According to Bocchini \& Frangopol (2013), resilience triangle helps to quantify the loss of resilience [6]. Assuming ' $t_{0}$ ' as the time when the disaster occurred, and ' $t_{r}$ ' as the time when the structure recovered fully, figure 1 shows the level of functionality of the structure on the $\mathrm{Y}$-axis and time on the $\mathrm{X}$-axis. The area of the shaded region (which is called the 
resilience triangle) in figure 1 is the approximate value of loss of resilience of an infrastructure due to the disaster. The remaining functionality or the capacity of the structure to withstand the shock is called 'robustness' [6]. In addition, the capacity of recovering quickly to the original condition after the shock is called 'rapidity' [6].

There are many studies that have quantified few metrics related to resilience of an infrastructure [30, 31]. However, resilience quantification still has many challenges. Previous studies have stated that resilience quantification is far from being sufficient for accurate quantification [32-34]. Existing literature have quantified mainly two dimensions of resilience: robustness and rapidity, because they are more quantifiable dimensions than remaining two: resourcefulness and redundancy, which are comparatively difficult to quantify because they deal with some qualitative factors [6]. Resourcefulness is defined as the capacity of making the necessary resources available for the structure to recover after a disaster $[3,6]$. Redundancy is defined as the substitutability of various components of the structure [6]. Resourcefulness and redundancy cause major problem on the accurate quantification of resilience because they deal with qualitative metrics like availability of resources to recover from a perturbation, substitutability of the infrastructure and its components etc. $[3,6]$. Therefore, more detailed review and assessment of various metrics and factors affecting all dimensions of resilience is needed for true representation of resilience and for its accurate quantification.

\subsection{Studies on Unification of Sustainability and Resilience}

Among available literature for unification purpose, Bocchini \& Frangopol (2013) applied an integrated perspective for analysis of resilience and sustainability of civil 
infrastructures [6]. They have explored a unified approach that uses concepts of probability of occurrence and risk for quantitative assessment of resilience and sustainability. They have quantified impacts that the infrastructure will have on the society in regular working circumstances (which sustainability assessment will focus on) and impacts after hazardous events and disasters (which resilience assessment will focus on) using their probabilities of occurrence. Similarly, Roostaie \& Nawari (2019) indicated creating a comprehensive structure for sustainability and resilience in order to achieve enhanced resilience at minimal environmental impact [7]. The analysis explored the idea of sustainability and resilience as well as interaction between the two definitions to discuss the idea of developing a unified framework. Roostaie and Nawari (2019) also concluded that to incorporate resilience metrics, that were not originally considered, the process needs an establishment of a new integrated assessment method or a detailed enhancement of existing sustainability frameworks [7]. Moreover, in order to effectively create a unified system, the direct participation of various stakeholders at all phases is essential [7]. However, both studies have indicated the necessity of adding more metrics and the need of a systematic methodology that can execute the accurate integration.

Quantification is crucial for understanding and improving sustainability and resilience, and is sometimes focused on measures or indicators, as it is often difficult to calculate and quantify all the indicators associated with both concepts in real terms [35]. For effective unification: i) a simultaneous assessment of both concepts; ii) analysis of effects on them when there are changes in design parameters; iii) better understanding of mechanisms related to building and its components, as well as iv) linking building to social structures of built environment, are required [3,5-7]. Their integration can be more reliable 
and can provide feasible plan of action for future implementations only when all factors mentioned above are considered and studied in proper details [23].

Results from past experiences have shown that considering sustainability and resilience as independent concepts is not a good solution for optimizing building design and construction. For instance, even when New York City had one of the world's largest sets of Leadership in Energy and Environmental Design (LEED) certified green buildings, it still faced more than $\$ 19$ billion in losses as a consequence of Hurricane Sandy [36]. These green buildings, as noted by Zolli and Healy (2012), are buildings having comparatively lesser environmental effects but, could not aptly adapt and react to the surrounding environmental impacts [37]. This example perfectly sums up the necessity of developing a framework that addresses both concepts simultaneously while designing any infrastructure so that it performs as expected during its life span. Moreover, the above example also clarifies that designing a building that is sustainable and being certified by widely used rating systems like LEED is not sufficient and is not the optimal design solution because such rating systems are missing another side of the building design which is the concept of resilience. Therefore, some scholars have criticized such certification systems for lacking the unified perspective [38]. 


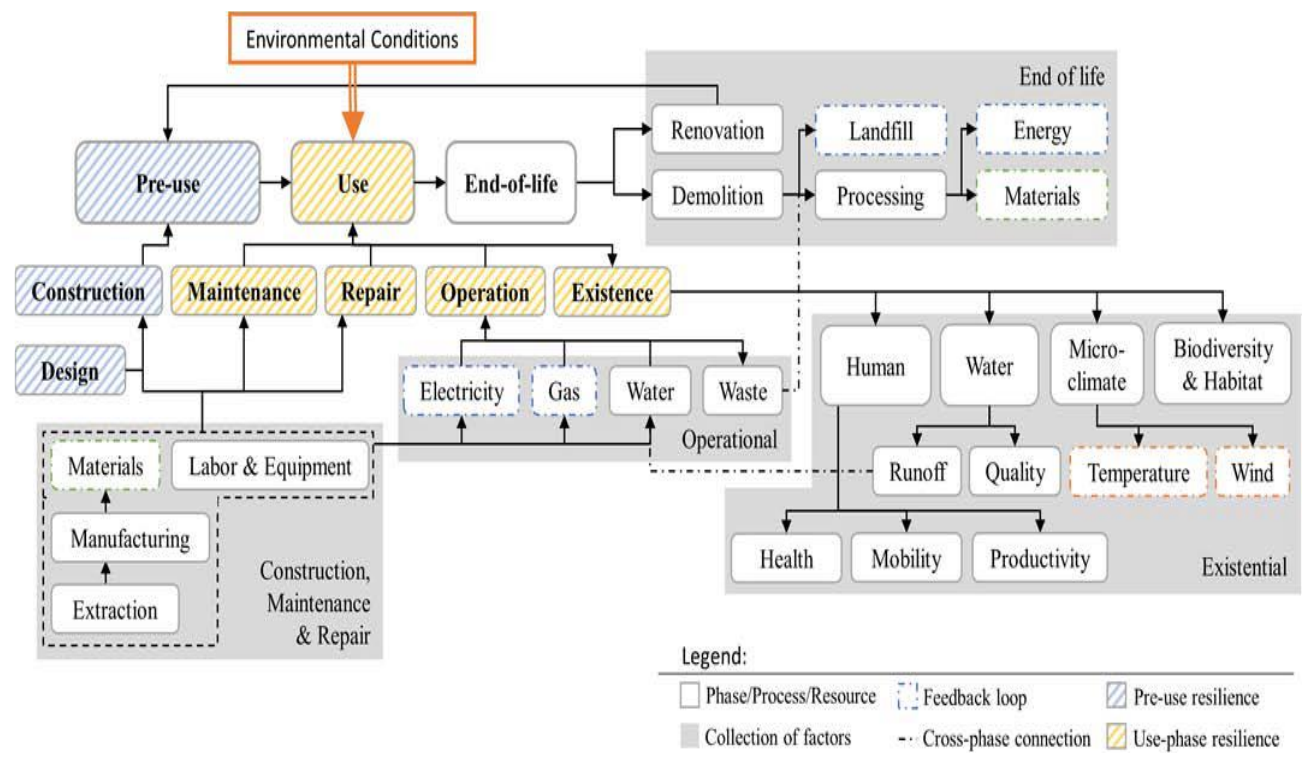

\section{Figure 2: Scope of sustainability factors for building and their connection to resilience [3]}

Sustainability and resilience of civil infrastructures are affected by several different factors as shown in figure 2 [3]. For different phases of an infrastructure (like planning, design, construction etc.), such factors contribute in determining all the possible metrics for assessment of both concepts. Diversity, performance, ability to adapt, and unity are factors that affect system resilience [3]. All these elements also affect system sustainability, indicating correlation between the two. The major gap between sustainability and resilience is that redundancy strengthens the resilience of an infrastructure, but regarding consumption of available resources, it weakens sustainability of the system [35, 39, 40]. Moreover, sustainability focuses on the events that the structure will face under normal operational circumstances and with low impacts on the structure (but certain of their occurrence) [6]. On the other hand, resilience focuses on events that the infrastructure might experience during its lifecycle, and have high impacts on the infrastructure (but uncertain of their occurrence) [6]. 


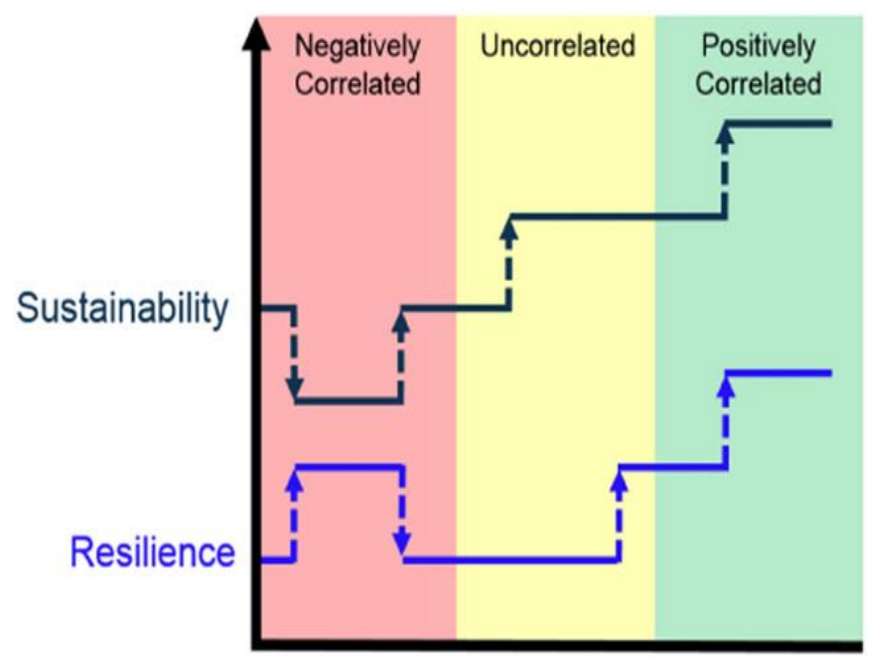

Figure 3: Sustainability and resilience as separate efforts: approaches to sustainability and resilience can either be negatively correlated, uncorrelated, or positively correlated [22]

According to Marchese 2018, the concept of sustainability and resilience could be interrelated (either positively or negatively) or they could be totally independent with each other depending on the infrastructure, which is shown in the figure 3 [22]. Moreover, unification of sustainability and resilience should focus on main issues such as [41]:

- how to identify and define key factors and components of both concepts

- how to analyze and track their integration process

- how the interactions among the important factors of each of them affects various areas of society, economy and environment

- how to recognize and involve stakeholders in the creation of such unified framework etc.

Therefore, based on the literature, to effectively unify sustainability and resilience concept for an infrastructure system, a systematic framework should be developed that can address all possible metrics associated with their quantification and common critical factors affecting both of them $[3,5-7,42]$. Only then, it will be possible to come up with a unified 
approach that can integrate them for any infrastructure systems. Another problem with their unification is that most of the academic literature and concerned stakeholders analyze either sustainability or resilience i.e. individually and not in an integrated way, which is why the design becomes much less effective than it should have been $[3,6,7,23,38]$. So, integration of both concepts during design phase is important to get the best out of a design. Thus, it is crucial to focus future research on their unification, especially in context of building design and construction.

\subsection{Knowledge Gap in the Literature}

Resilience and sustainability are two separate aspects which are challenging the world of researchers since long. To quantify these two concepts is a difficult task to execute $[18,43]$. As such, to ultimately merge and unify them together through a single framework still remains a milestone that only few literature have tried to achieve [44]. The studies on sustainability have assisted in modifying and creating certification systems that focus on sustainability assessment of a building like Leadership in Energy and Environmental Design (LEED) rating standards. Additionally, studies on resilience have assisted in creating and modifying the codes and regulations like Florida Building Codes. But, even with so many existing studies on quantification of each concept individually, there is a lack of single effective quantification and unification methodology that can integrate both concepts accurately, especially in case of Buildings [3, 5-7].

There are many qualitative factors that need to be addressed for a building design and construction (like human comfort). So, in context of buildings, the relationship between sustainability and resilience becomes even more complex than they are for other 
systems (like transportation). Moreover, researchers who have, to some extent, incorporated both concepts together, have been unable to develop a systematic method for their quantification [5]. Specially for building systems, there is a need to identify critical metrics that accurately represent and aid in the process of integrating both concepts. Some studies have pointed out that the currently implemented approaches need to be modified for perfect integration of sustainability and resilience [6] [7]. For example, conventional approaches need to consider and add more variables or metrics for more effective integration; which will help to quantify every possible aspect related with building sustainability and resilience [6] [7].

In addition, it is very challenging to develop a unified framework that will seamlessly merge the two sciences: sustainability and resilience. Such an integrated framework needs to be adjusted to adapt to the design of each scenario, location, surrounding environment, and type of natural disasters vulnerable to that region [42]. Existing studies have shown that there can be two ways to unify sustainability and resilience: either merging resilience metrics to sustainability assessment system or integrating sustainability metrics to resilience assessment system [3, 7, 41]. While both concepts have many common goals, research that aim to integrate them will have to consider ultimate future goal of the system being examined and assure that the planned goal is achieved perfectly [41].

A framework that can successfully quantify and integrate sustainability and resilience metrics with proper consideration of all the factors impacting both concepts, can help in the decision-making process. Such an integration for decision making process has been performed by Bocchini \& Frangopol (2013) with focus on transportation networks 
and bridge systems, but the study also indicates how it can be done for various civil infrastructure systems like buildings [6]. Previous studies have also shown the lack of effective framework for the quantification of sustainability [18, 45] and resilience [35, 43] and have revealed the intricacies and difficulties associated with their integration $[3,5,42$, 44]. Moreover, literature which tried to quantify and integrate them have been unable to do so with proper consideration of critical factors and their interdependencies with each other. Therefore, this field of research is comparatively in initial phases of its development where a lot of further research are necessary for significant progress in the quantification and integration of sustainability and resilience.

\subsection{Conceptual Framework}

Based on existing literature, making an infrastructure sustainable essentially means:

- maximize infrastructure value by minimizing costs and maximizing benefits

- reducing the consumption of resources as much as possible during its expected life cycle

- making the components of the infrastructure, where possible, recyclable or reusable

- lessening their impact on the natural environment

- increasing the comfortability, safety and health of people using the infrastructures

- easily adapting to the surrounding environment without creating any disturbance etc.

To quantify sustainability, all the above-mentioned perspectives need to be linked together. Otherwise, the quantification will be unable to represent the actual sustainability value of the respective infrastructure. 
Based on existing literature, making an infrastructure resilient fundamentally means:

- increasing structural integrity and performance of the infrastructure against both natural and manmade hazards or against any type of perturbation to the system; which ultimately means making it robust.

- designing and constructing the infrastructure in a way to increase the pace and rate of recovery to get back to the normal operating conditions after facing the disturbance; which ultimately means building in a way to help increase rapidity of the infrastructure to bounce back after a disturbance.

- designing and selecting infrastructure in a way to increase substitutability of the infrastructure system and its components so that it'll be easier to substitute the infrastructure and its components even if a disaster destroys them; which means increasing redundancy of the infrastructure.

- increasing availability of the resources to deal with any possible future hazards or disasters in a convenient and effective way; which means increasing resourcefulness of the infrastructure systems.

For accurate quantification of infrastructure resilience value, above mentioned parameters need to be addressed and merged properly with necessary details. Otherwise, quantification value obtained after analysis will be unable to represent real value of resilience of the concerned infrastructure.

Therefore, keeping all the above-mentioned factors in consideration and based on existing studies, the accurate quantification of sustainability and resilience and their 
ultimate unification has a lot of problems remaining to be solved. Some of the major issues for the quantification and unification are as follows:

- identifying all the metrics impacting sustainability and resilience quantification

- major common factors that significantly contribute to quantification of both concepts

- lack of a single effective systematic methodology for their quantification and unification $[3,5-7]$

- interrelationship between sustainability and resilience for the infrastructure being considered: positively correlated, negatively correlated or totally independent concepts [22]

- some of the dimensions are comparatively difficult to quantify because they deal with qualitative aspects like social dimension of sustainability and resourcefulness dimension of resilience.

From information available through the review of literature on the quantification of sustainability and resilience, it's clear that both concepts have their own complexities and problems associated with them. Many existing studies have tried to quantify both concepts separately, but such studies are not sufficient for accurate quantification. Many scholars have mentioned this problem of lack of accurate methodology to quantify sustainability $[18,45]$ and resilience $[35,43]$ and lack of an effective framework to ultimately integrate both concepts $[3,5,42,44]$. Therefore, quantification and unification of sustainability and resilience is getting a lot of attention from the world of researchers. However, due to 
complex nature of their interrelationship and lack of identification of all significant metrics for accurate analysis, their integration is in nascent phase and needs more future studies.
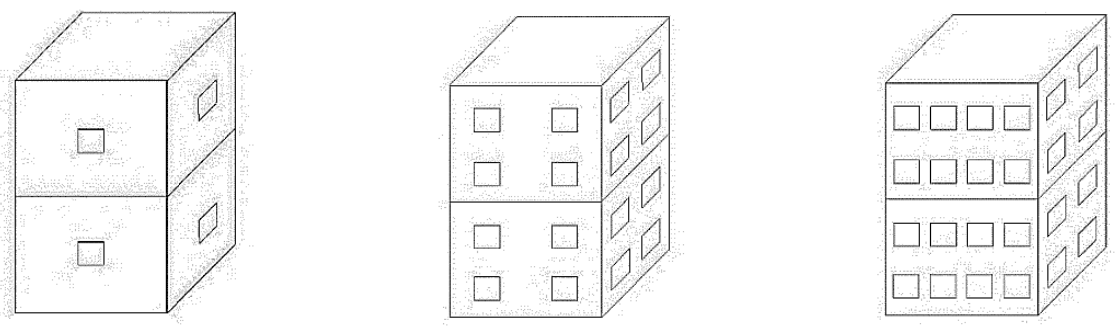

Option 1: $\mathbf{S} \approx$ low; $\mathbf{R} \approx$ high Option $2: \mathbf{S} \approx$ high; $\mathbf{R} \approx$ high Option $3: \mathbf{S} \approx$ high; $\mathbf{R} \approx$ low Figure 4: Various building design options considering opening [Note: S: Sustainability value regarding sunlight, R: resilience value regarding structural integrity]

The challenging part for the integration of sustainability and resilience is to find the optimal design solution that can, where possible, unify both concepts without weakening any one of them [5-7]. As shown in figure 4 above, even if we only consider one component of a building (i.e. openings), for the same building there will be many alternatives available for its design and construction with regard to openings. However, only a certain range of openings will be able to provide higher values of both $\mathrm{S}$ and $\mathrm{R}$ (i.e. enhancing sustainability and resilience at the same time). This is the most challenging part in the unification. The possible implications of each design alternatives, as shown in figure 4 regarding openings, are:

- building option 1: too dark but, less vulnerable!

- building option 2: comfortable brightness, and resilient too? optimal range?

- building option 3: too bright but, more vulnerable! 
Therefore, building option 2 is the design that can enhance both concepts at the same time. Such simultaneous enhancement of sustainability and resilience should be the main goal of their unification.

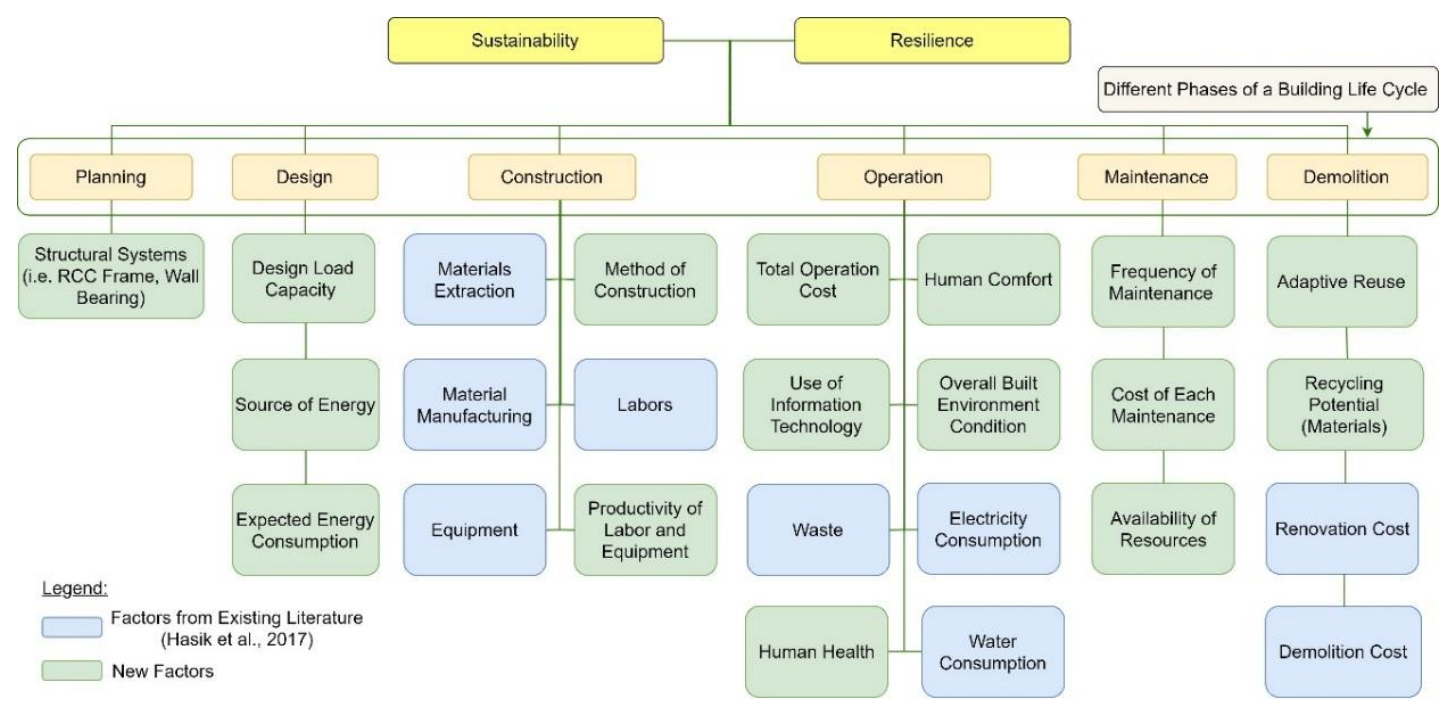

\section{Figure 5: Critical factors affecting sustainability and resilience during different phases of a building life cycle}

Figure 5 shows factors that need to be considered and analyzed for integration of sustainability and resilience in various phases of life cycle of an infrastructure (i.e. planning, design, construction, operation, maintenance and demolition phase). For planning phase, the most important factor to be addressed is structural system of the building (or type of building), which means whether the building is reinforced concrete (RC) framed structure or just unreinforced masonry buildings. This factor affects how the building will respond to various disasters and it also affects cost and expected lifespan of the building.

Factors that are important for design phase are design load capacity (or design structural load), energy sources to be used (electricity, natural gas, solar energy etc.) and 
amount of expected energy consumption. For construction phase, specifications of materials being used, methodology of construction being adopted (on-site/off-site construction), extraction of raw material for construction (cost and time associated with the extraction), material manufacturing cost, equipment being used for construction (cost and risk associated regarding equipment safety), cost of labors, productivity of equipment and labors (efficiency and effectiveness) are main factors to be considered.

Similarly, for operation phase, total operation cost of the building, human comfort level (for example: micro climate, temperature, facilities available in the building), information technology that are being used in the structure for smooth and effective operation, overall built environment condition (neighborhood environmental conditions), waste and its management, electricity and water consumption rate and human health (indoor air quality, sanitary conditions inside the building) are the major factors that will affect sustainability and resilience values. For maintenance phase, frequency and cost of maintenance, availability of the resources (whether different necessary resources are available and at what cost) affects sustainability and resilience of the structure. For demolition phase, cost of demolition, cost of renovation, capacity of reuse of the building and recycling potential of materials used for construction affects sustainability and resilience value of the structure. Therefore, such factors need to be considered for accurate quantification and effective integration of sustainability and resilience in context of buildings. 


\subsection{Summary of Literature}

The main goal of this study is to review literature focusing on challenges of quantification and unification of sustainability and resilience. The summary of the review is shown in table 1.

Table 1: Summary of studies on sustainability, resilience and their integration

\begin{tabular}{|c|c|c|}
\hline Concept & Key Insights & $\begin{array}{c}\text { Referenced } \\
\text { Papers }\end{array}$ \\
\hline $\begin{array}{l}\text { Sustainability of } \\
\text { an infrastructure }\end{array}$ & $\begin{array}{l}\text { Sustainability is a vital aspect that needs to } \\
\text { be considered for design and construction of } \\
\text { any civil infrastructures. It focuses on } \\
\text { fulfilling today's need without affecting the } \\
\text { need of future. In case of infrastructures, it } \\
\text { focuses mainly on reducing the effect of } \\
\text { such infrastructures in the natural } \\
\text { environment. }\end{array}$ & $\begin{array}{l}\text { [2]; [11]; [7]; [6]; } \\
\text { [13]; [3]; [18]; }\end{array}$ \\
\hline $\begin{array}{l}\text { Challenges in } \\
\text { quantification of } \\
\text { infrastructure } \\
\text { sustainability }\end{array}$ & $\begin{array}{l}\text { Main difficulties in sustainability } \\
\text { quantification are the dimensions that deal } \\
\text { with qualitative parameters: environmental } \\
\text { and social sustainability. For example: } \\
\text { social sustainability deals with human } \\
\text { comfort and safety level of an } \\
\text { infrastructure. }\end{array}$ & $\begin{array}{l}\text { [3]; [6]; [5]; [46]; } \\
{[22] ;[\text { [18]; [45]; }} \\
\text { [7] }\end{array}$ \\
\hline $\begin{array}{l}\text { Resilience of an } \\
\text { infrastructure }\end{array}$ & $\begin{array}{l}\text { Resilience is a crucial aspect that needs to } \\
\text { be considered for design and construction of } \\
\text { any civil infrastructures. In general, } \\
\text { resilience focuses on developing the ability } \\
\text { to bounce back to normal situation after } \\
\text { facing sudden external shock or disturbance. } \\
\text { In case of infrastructures, resilience focuses } \\
\text { on enhancing the capacity of infrastructures } \\
\text { to deal with any possible hazards in an } \\
\text { effective and efficient manner. }\end{array}$ & $\begin{array}{l}\text { [37]; [21]; [47]; } \\
\text { [6]; [3]; [34]; [19]; } \\
\text { [40]; [28]; [24] }\end{array}$ \\
\hline $\begin{array}{l}\text { Challenges in } \\
\text { quantification of } \\
\text { infrastructure } \\
\text { resilience }\end{array}$ & $\begin{array}{l}\text { Main difficulties in resilience quantification } \\
\text { are quantifying the dimensions that deal } \\
\text { with qualitative parameters: resourcefulness } \\
\text { and redundancy. For example: } \\
\text { resourcefulness deals with availability of } \\
\text { various resources to deal with a certain } \\
\text { disaster and their mobility as well as } \\
\text { efficiency. }\end{array}$ & $\begin{array}{l}\text { [30]; [39]; [29]; } \\
\text { [48]; [35]; [33]; } \\
\text { [31]; [6]; [3]; [7]; } \\
\text { [41]; [32] }\end{array}$ \\
\hline
\end{tabular}




\begin{tabular}{|l|l|l|}
\hline $\begin{array}{l}\text { Unifying } \\
\text { Sustainability and } \\
\text { resilience of an } \\
\text { infrastructure } \\
\text { and current } \\
\text { knowledge gap }\end{array}$ & $\begin{array}{l}\text { As both concepts are crucial to sustain an } \\
\text { infrastructure for longer duration, their } \\
\text { concurrent assessment with anifying } \\
\text { approach is important. Lack of a single } \\
\text { effective systematic framework to } \\
\text { simultaneously assess these two concepts } \\
\text { while designing and constructing an } \\
\text { infrastructure is the main gap in current } \\
\text { literature. Another challenge is to accurately } \\
\text { establish their interrelationship, because a } \\
\text { single decision could reinforce one and } \\
\text { undermine another. Moreover, most }\end{array}$ & $\begin{array}{l}{[23] ;[49] ;[7] ;} \\
{[20] ;[12] ;[44] ;}\end{array}$ \\
& $\begin{array}{l}\text { academic literature and stakeholders } \\
\text { analyze either sustainability or resilience i.e. } \\
\text { individually and not with an integrated } \\
\text { perspective, which is why the design }\end{array}$ & \\
& $\begin{array}{l}\text { becomes much less effective than it should } \\
\text { be. }\end{array}$ & \\
\hline
\end{tabular}




\section{CHAPTER III}

\section{UNIFYING ASSESSMENTS FOR STRUCTURAL MASONRY}

\subsection{Experimental Setup}

In this study, we adopt a novel approach to combine the concept of sustainability and resilience for a building system. To simplify our approach, an unreinforced masonry structure is selected and changes in sustainability (i.e. energy consumption) and resilience (i.e. story drifts related to structural integrity) indicators are observed by modifying the openings. This novel approach facilitates the monitoring of changes in sustainability and resilience indicators with respect to a unique standard of reference (i.e. openings). The building structure considered for the analysis is an unreinforced masonry structure because in such a building, openings may affect both assessment results simultaneously. All other design elements are fixed. For quantification of sustainability, electricity consumption is considered because variations in openings may significantly affect the electricity consumption of a building. Energy simulation is performed for sustainability quantification. For resilience quantification, story drifts due to earthquake load are observed and recorded. The story drift represents the structural integrity and robustness of the building against external shocks. Structural analysis is performed for resilience quantification.

\subsection{Building Data Description}

In this study, for integration of sustainability and resilience in context of a building, a masonry low-rise multi-family residential building is analyzed. The plan of an existing building from Nepal is taken for the analysis. The building has 2 floors and an attic. Length of the building is $24^{\prime}-9^{\prime \prime}$ and breadth is $19^{\prime}-1{ }^{\prime \prime}$. Total height of the building (from plinth 
level up to ridge of the roof) is $24^{\prime}-5^{\prime \prime}$. Material used for construction is brick masonry in cement sand mortar. The main entrance of the building is on the south elevation.

\subsection{Details of Analysis}

For sustainability assessment, using eQUEST software (Quick Energy Simulation Tool), this study has analyzed annual electric energy consumption for various uses such as space heating, space cooling, etc. First, the original building plan is modeled on eQUEST. Input parameters used for modeling purposes are building plan, envelope, building type and location. Other building components, such as heating and cooling systems, are modeled as default by the software based on building type and plan. Then, the original building model (or base case scenario) is modified to create twelve different cases based on changes in openings. Results from energy simulation are obtained in the form of annual electricity consumption for different activities.

For resilience assessment, Extended Three-Dimensional Analysis of Building System (ETABS) software is used. By modeling the building on ETABS, this study has analyzed the story drift of the building against earthquake load. For modeling purposes, Xdirection is considered as the direction parallel to the length of the building, and Y-direction is considered as the direction parallel to the breadth of the building. The building is tested against a 475-year return period earthquake. Design parameters used for modeling purposes are as per the Nepal Building Code. The boundary condition is fixed at plinth level. ETABS frame and slab elements are used for the modeling. Base case model is modified by varying openings to create twelve new case scenarios. Openings of each scenario created on ETABS are the same as the respective openings used in eQUEST 
modeling for sustainability assessment. Structural analysis is performed while modifying openings and respective values of story drifts are recorded.

\subsection{Modeling for Sustainability Assessment}

Models created for sustainability analysis are shown below. Four elevations of the base case scenario (original model) are as follows:

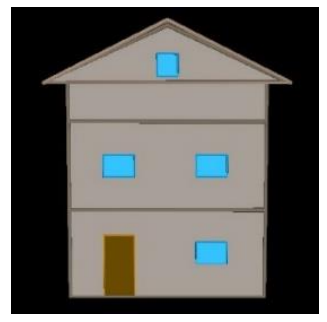

East

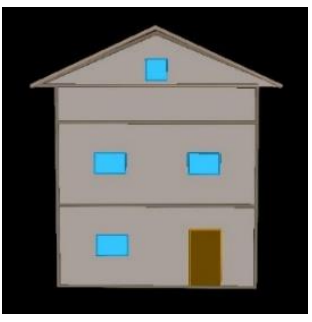

West

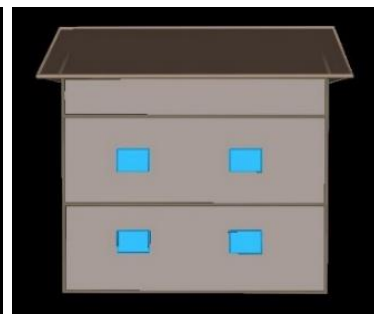

North

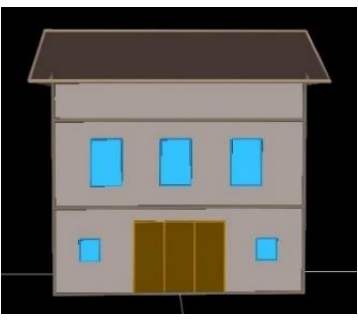

South

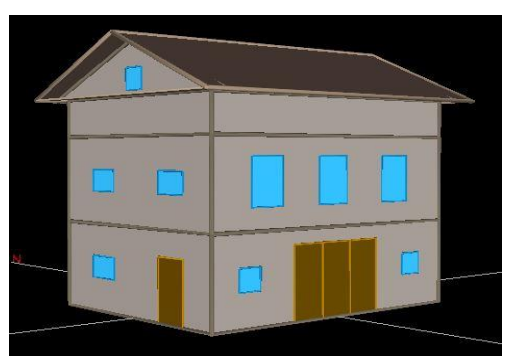

Figure 6: Four elevations and 3D view of original building model on eQUEST (base case scenario)

Size of various openings are changed in different walls and twelve new models are

created. Walls where size of openings are changed (for different cases) are shown below: 


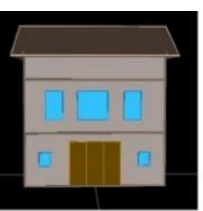

C1 (S)

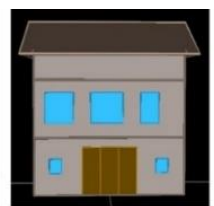

C2 (S)

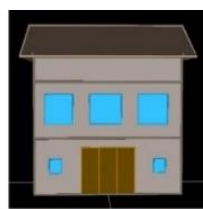

C3 (S)

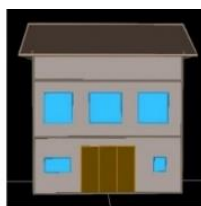

C4 (S)

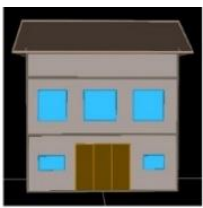

C5 (S)

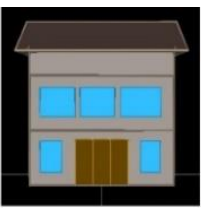

C6 (S)

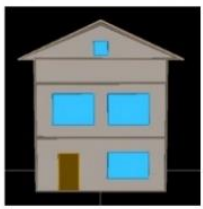

C7 (E)

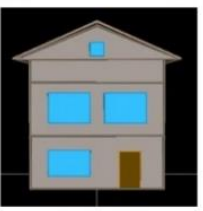

C8 $(\mathrm{W})$

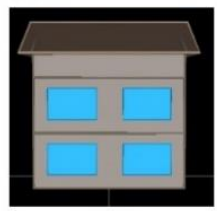

C9 (N)

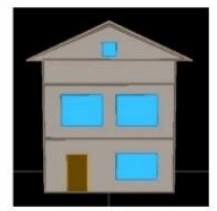

$\mathrm{C} 10(\mathrm{E})$

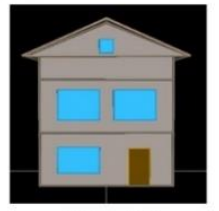

C10 (W)

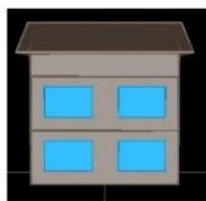

$\mathrm{C} 11(\mathrm{~N})$

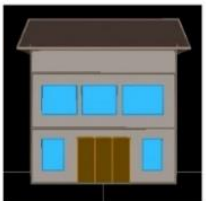

C11 (S)

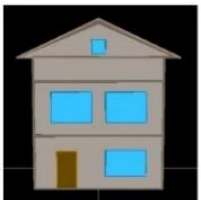

$\mathrm{C} 12(\mathrm{E})$

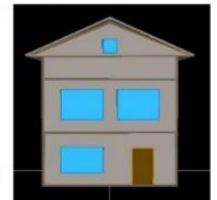

$\mathrm{C} 12(\mathrm{~W})$

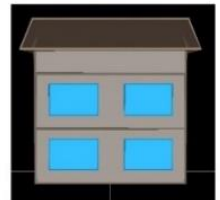

$\mathrm{C} 12(\mathrm{~N})$

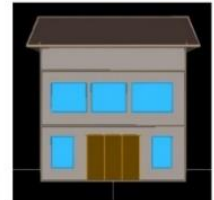

$\mathrm{C} 12(\mathrm{~S})$

Figure 7: Walls of different case scenarios where openings are modified (with respect to base case) for sustainability assessment

$* * E=$ East,$W=$ West,$N=$ North, $S=$ South

\subsection{Modeling for Resilience Assessment}

Models created for resilience analysis are shown below. Four elevations of the base case scenario (original model) are as follows:

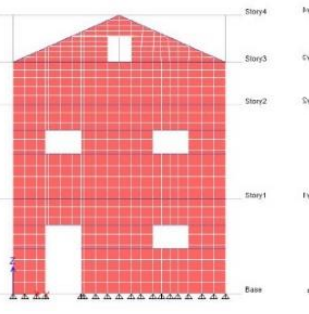

East

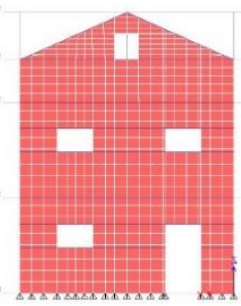

West

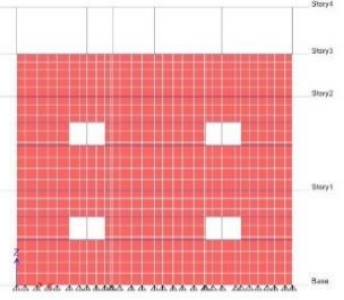

North

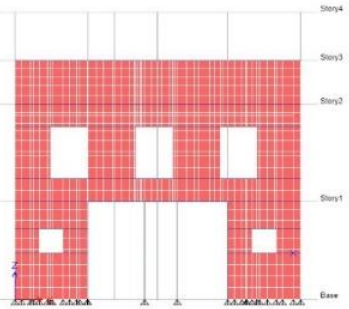

South 


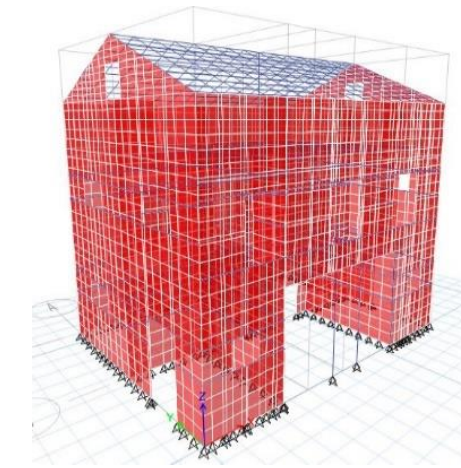

Figure 8: Four elevations and 3D view of original building model on ETABS (base case scenario)

Size of various openings are changed in different walls and twelve new models are created. Walls where size of openings are changed (for different cases) are shown below:
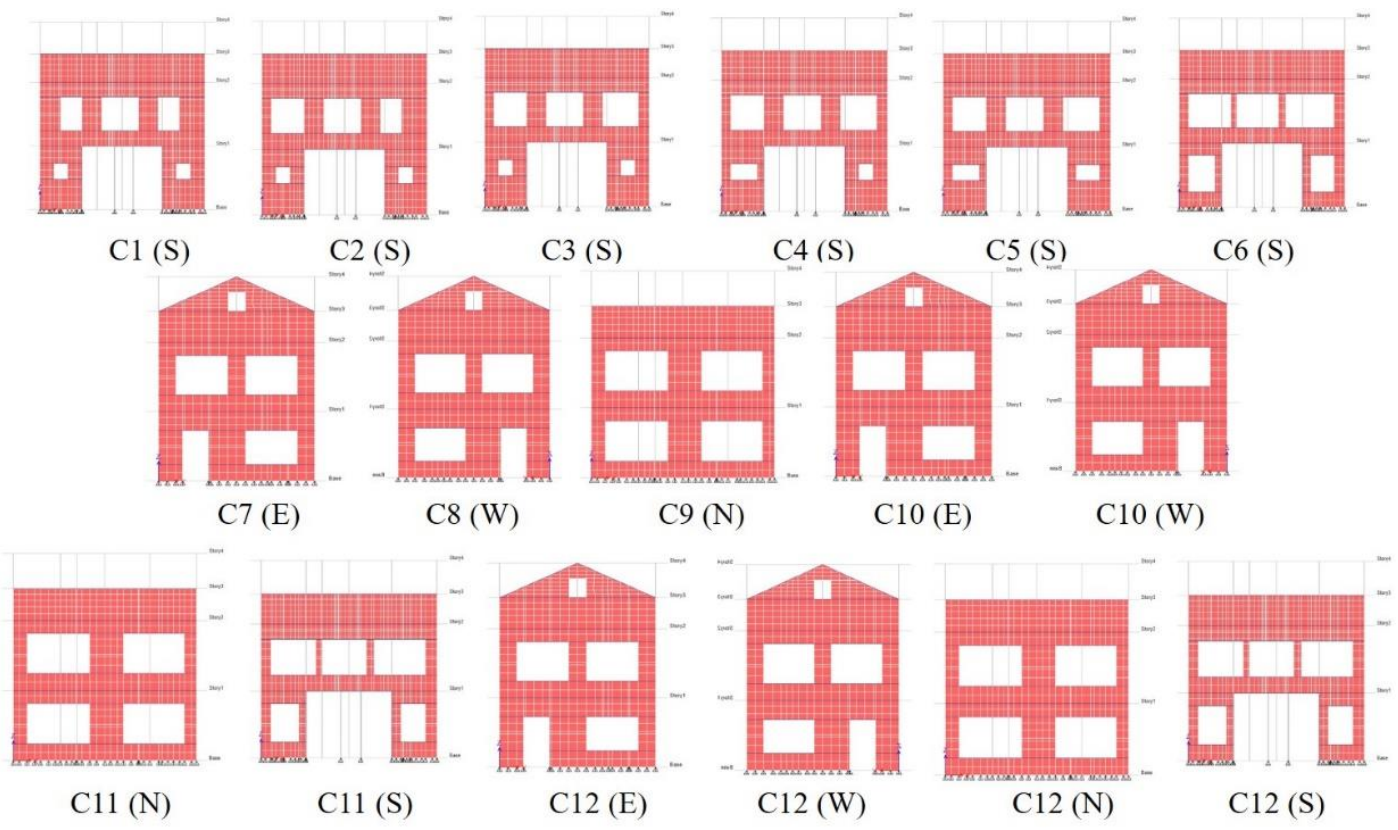

Figure 9: Walls of different case scenarios where openings are modified (with respect to base case) for resilience assessment

$* * E=$ East,$W=$ West,$N=$ North, $S=$ South 


\subsection{Details of Opening}

Total surface areas are observed to be 470.25 sq. ft. both for south and north walls, whereas both East and West walls are 400.75 sq. ft.

Table 2: Details of Percentage Opening in Each Scenario

\begin{tabular}{|c|c|c|c|c|c|c|c|c|c|c|c|}
\hline & & \multicolumn{10}{|c|}{ Openings } \\
\hline $\begin{array}{c}\text { Walls } \\
\text { Affected }\end{array}$ & $\begin{array}{c}\text { Scenario } \\
\text { Description }\end{array}$ & $\begin{array}{l}5 w+3 d \\
\text { (S) (sqft) }\end{array}$ & $\begin{array}{c}4 w(\mathrm{~N}) \\
(\mathrm{sqft})\end{array}$ & $\begin{array}{c}4 w+1 \\
d(\mathrm{E}) \\
(\mathrm{sqft})\end{array}$ & $\begin{array}{c}4 w+1 \\
d(\mathrm{~W}) \\
(\mathrm{sqft})\end{array}$ & $\begin{array}{l}\text { Total } \\
\text { (sqft) }\end{array}$ & $\begin{array}{l}\% \\
(\mathrm{~S})\end{array}$ & $\begin{array}{c}\% \\
(\mathrm{~N})\end{array}$ & $\begin{array}{c}\% \\
(\mathrm{E})\end{array}$ & $\begin{array}{c}\% \\
(\mathbf{W})\end{array}$ & $\begin{array}{c}\% \\
\text { (Total) }\end{array}$ \\
\hline $\begin{array}{l}\text { Original } \\
\text { Building }\end{array}$ & $\begin{array}{c}\text { Base Case } \\
\left(\mathrm{C}_{0}\right)\end{array}$ & 106.28 & 24 & 35.01 & 35.01 & 200.3 & 22.60 & 5.10 & 8.74 & 8.74 & 11.50 \\
\hline $\mathbf{S}$ & Case $1\left(C_{1}\right)$ & 116.18 & 24 & 35.01 & 35.01 & 210.2 & 24.71 & 5.10 & 8.74 & 8.74 & 12.07 \\
\hline $\mathbf{S}$ & Case $2\left(C_{2}\right)$ & 123.07 & 24 & 35.01 & 35.01 & 217.09 & 26.17 & 5.10 & 8.74 & 8.74 & 12.46 \\
\hline $\mathbf{S}$ & Case $3\left(C_{3}\right)$ & 131.61 & 24 & 35.01 & 35.01 & 225.63 & 27.99 & 5.10 & 8.74 & 8.74 & 12.95 \\
\hline $\mathbf{S}$ & Case $4\left(C_{4}\right)$ & 136.09 & 24 & 35.01 & 35.01 & 230.11 & 28.94 & 5.10 & 8.74 & 8.74 & 13.21 \\
\hline $\mathbf{S}$ & Case $5\left(C_{5}\right)$ & 138.71 & 24 & 35.01 & 35.01 & 232.73 & 29.50 & 5.10 & 8.74 & 8.74 & 13.36 \\
\hline $\mathbf{S}$ & Case $6\left(C_{6}\right)$ & 172.12 & 24 & 35.01 & 35.01 & 266.14 & 36.60 & 5.10 & 8.74 & 8.74 & 15.28 \\
\hline $\mathbf{E}$ & Case $7\left(C_{7}\right)$ & 106.28 & 24 & 99.19 & 35.01 & 264.48 & 22.60 & 5.10 & 24.75 & 8.74 & 15.18 \\
\hline $\mathbf{W}$ & Case $8\left(C_{8}\right)$ & 106.28 & 24 & 35.01 & 99.19 & 264.48 & 22.60 & 5.10 & 8.74 & $\begin{array}{c}24.7 \\
5\end{array}$ & 15.18 \\
\hline $\mathbf{N}$ & Case $9\left(C_{9}\right)$ & 106.28 & 144.83 & 35.01 & 35.01 & 321.13 & 22.60 & 30.80 & 8.74 & 8.74 & 18.43 \\
\hline $\mathbf{E} \& \mathbf{W}$ & $\begin{array}{c}\text { Case 10 } \\
\left(\mathrm{C}_{10}\right)\end{array}$ & 106.28 & 24 & 99.19 & 99.19 & 328.66 & 22.60 & 5.10 & 24.75 & $\begin{array}{c}24.7 \\
5\end{array}$ & 18.87 \\
\hline $\mathbf{N} \& \mathbf{S}$ & $\begin{array}{c}\text { Case } 11 \\
\left(C_{11}\right)\end{array}$ & 172.12 & 144.83 & 35.01 & 35.01 & 386.97 & 36.60 & 30.80 & 8.74 & 8.74 & 22.21 \\
\hline $\begin{array}{c}\mathbf{S}, \mathbf{N}, \\
\mathbf{E} \& \mathbf{W}\end{array}$ & $\begin{array}{c}\text { Case } 12 \\
\left(C_{12}\right)\end{array}$ & 172.12 & 144.83 & 99.19 & 99.19 & 515.33 & 36.60 & 30.80 & 24.75 & $\begin{array}{c}24.7 \\
5\end{array}$ & 29.58 \\
\hline
\end{tabular}

$* * S=$ South wall $; N=$ North wall $; E=$ East wall $; W=$ West wall $; w=$ Windows $; d=$ Doors

\subsection{Experimental Results}

In this section, results obtained from different experimental setups are reported. In

particular, the changes observed in sustainability indicators i.e. space heating, total electricity, heat pump supply, hot water, ventilation fans, area lights and miscellaneous 
equipment along with the corresponding openings are presented in table 2. Likewise, changes in resilience indicators i.e. story drifts both in $\mathrm{X}$ and $\mathrm{Y}$ direction for each story are reported in table 3.

Table 3: Sustainability Assessment Results for All Cases

\begin{tabular}{|c|c|c|c|c|c|c|c|c|}
\hline \multirow[b]{2}{*}{$\begin{array}{c}\text { Building } \\
\text { Model }\end{array}$} & \multicolumn{8}{|c|}{ Annual Electricity Consumption for different activities (kWh) } \\
\hline & $\begin{array}{c}\text { Space } \\
\text { Heating } \\
\left(\mathbf{S}_{\mathrm{SH}}\right)\end{array}$ & $\begin{array}{c}\text { Total } \\
\text { Electricity } \\
\left(\mathbf{S}_{\mathrm{TE}}\right)\end{array}$ & $\begin{array}{c}\text { Heat } \\
\text { Pump } \\
\text { (HP) } \\
\text { Suppl } \\
\text { y (S (SP) }\end{array}$ & $\begin{array}{l}\text { Hot } \\
\text { Water } \\
\text { (SHW) }\end{array}$ & $\begin{array}{c}\text { Vent- } \\
\text { ilation } \\
\text { Fan } \\
\text { (SVF) }\end{array}$ & $\begin{array}{l}\text { Misc. } \\
\text { Equip. } \\
\left(\text { S }_{\mathrm{ME}}\right)\end{array}$ & $\begin{array}{c}\text { Area } \\
\text { Lights } \\
\left(\mathbf{S}_{\mathrm{AL}}\right)\end{array}$ & $\begin{array}{c}\text { Space } \\
\text { Cooling } \\
\text { (SSC) }\end{array}$ \\
\hline $\mathrm{C}_{0}$ & 12.60 & $9,423.30$ & 2.30 & $1,203.80$ & 628.00 & $1,471.20$ & $1,882.80$ & $4,222.60$ \\
\hline $\mathbf{C}_{1}$ & 11.30 & $9,423.50$ & 2.30 & $1,203.30$ & 685.70 & $1,471.20$ & $1,882.80$ & $4,067.00$ \\
\hline $\mathbf{C}_{2}$ & 10.90 & $9,469.50$ & 2.30 & $1,203.10$ & 715.30 & $1,471.20$ & $1,882.80$ & $4,184.10$ \\
\hline $\mathbf{C}_{3}$ & 10.50 & $9,657.30$ & 2.30 & $1,202.80$ & 754.40 & $1,471.20$ & $1,882.80$ & $4,333.30$ \\
\hline $\mathbf{C}_{4}$ & 10.50 & $9,726.10$ & 2.30 & $1,202.50$ & 765.50 & $1,471.20$ & $1,882.80$ & $4,391.40$ \\
\hline $\mathrm{C}_{5}$ & 10.50 & $9,767.40$ & 2.30 & $1,202.30$ & 772.10 & $1,471.20$ & $1,882.80$ & $4,426.30$ \\
\hline $\mathrm{C}_{6}$ & 10.00 & $10,470.00$ & 0.00 & $1,200.00$ & 880.00 & $1,471.20$ & $1,882.80$ & $5,020.00$ \\
\hline $\mathrm{C}_{7}$ & 10.00 & $10,230.00$ & 0.00 & $1,200.00$ & 780.00 & $1,471.20$ & $1,882.80$ & $4,880.00$ \\
\hline $\mathrm{C}_{8}$ & 10.00 & $10,390.00$ & 0.00 & $1,200.00$ & 820.00 & $1,471.20$ & $1,882.80$ & $5,000.00$ \\
\hline $\mathrm{C}_{9}$ & 20.00 & $10,070.00$ & 0.00 & $1,200.00$ & 720.00 & $1,471.20$ & $1,882.80$ & $4,770.00$ \\
\hline $\mathrm{C}_{10}$ & 10.00 & $10,940.00$ & 0.00 & $1,200.00$ & 870.00 & $1,471.20$ & $1,882.80$ & $5,500.00$ \\
\hline $\mathrm{C}_{11}$ & 10.00 & $10,990.00$ & 0.00 & $1,200.00$ & 970.00 & $1,471.20$ & $1,882.80$ & $5,450.00$ \\
\hline $\mathrm{C}_{12}$ & 20.00 & $12,170.00$ & 0.00 & $1,200.00$ & $1,120.00$ & $1,471.20$ & $1,882.80$ & $6,480.00$ \\
\hline
\end{tabular}

$* * S_{X X}=$ Sustainability value for indicator $X X$

The values in table 3 show annual electricity consumption in Kilowatt hour (kWh) of different activities for each model. Figure 10 is the graphical representation of the results shown in table 3 . The graphs in figure 10 are divided based on changes of openings made on various walls. Results for changes in the south wall (i.e. from $\mathrm{C}_{0}$ to $\mathrm{C}_{6}$ ) are shown in figure 10 (a). Similarly, results for changes made in other walls (i.e. from $\mathrm{C}_{7}$ to $\mathrm{C}_{9}$ ) are 
shown in figure 10 (b). Results for simultaneous changes in various walls (i.e. from $\mathrm{C}_{10}$ to $\mathrm{C}_{12}$ ) are shown in figure $10(\mathrm{c})$. In addition, figure $10(\mathrm{~d})$ shows percentage change from base case for changes in the south wall and figure 10 (e) shows percentage change from base case for changes in other walls. For the analysis on eQUEST, the building was simulated for weather data of Miami because the software can only provide the weather data for location inside the US. The weather data was fixed based on the location. Results showed that with additional openings in the building, values of total annual electricity consumption and annual electricity consumption for ventilation fan decreased for all cases except from $\mathrm{C}_{6}$ to $\mathrm{C}_{7}$ and from $\mathrm{C}_{8}$ to $\mathrm{C}_{9}$. Moreover, annual electricity consumption for space cooling dropped with additional openings from $\mathrm{C}_{0}$ to $\mathrm{C}_{1}$. However, further increase in openings lead to higher consumption: from $C_{1}$ to $C_{6}$ and from $C_{7}$ to $C_{12}$. The value of annual electricity consumption for heat pump supply was constant from $\mathrm{C}_{0}$ to $\mathrm{C}_{5}$, but from $\mathrm{C}_{5}$ to $\mathrm{C}_{12}$ the value dropped to zero. All other values of annual electricity consumption for hot water, miscellaneous equipment and area lights were constant no matter the changes in openings provided.

The most unusual pattern was observed for the values of annual electricity consumption for space heating. As shown in figure 10 (a), from $\mathrm{C}_{0}$ to $\mathrm{C}_{6}$, values of annual electricity consumption for space heating kept decreasing with additional openings. However, from $\mathrm{C}_{7}$ to $\mathrm{C}_{12}$, the value of space heating electricity consumption showed different patterns while increasing the opening. From $\mathrm{C}_{8}$ to $\mathrm{C}_{9}$, the value of annual electricity consumption for space heating increased by a significant margin. Another unusual pattern of space heating was observed from $C_{9}$ to $C_{10}$, where the value decreased by a significant number within a very short range of total percentage opening $(+0.44 \%)$. 
Then, from $\mathrm{C}_{10}$ to $\mathrm{C}_{11}$, the value of electricity consumption for space heating remained constant. Lastly, from $\mathrm{C}_{11}$ to $\mathrm{C}_{12}$, the value increased significantly. Results showed negative correlation between the electricity consumption for space heating and total percentage openings provided in the building for changes made in the south wall (-0.84). As shown in figure 10 (b), (c) and (e), the correlation changed when the changes were made in other walls. 
(a) Changes in South Wall

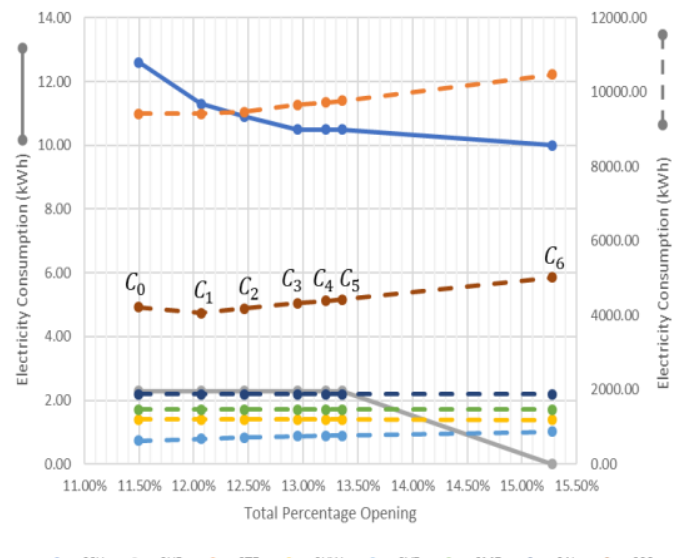

(b) Changes in remaining walls

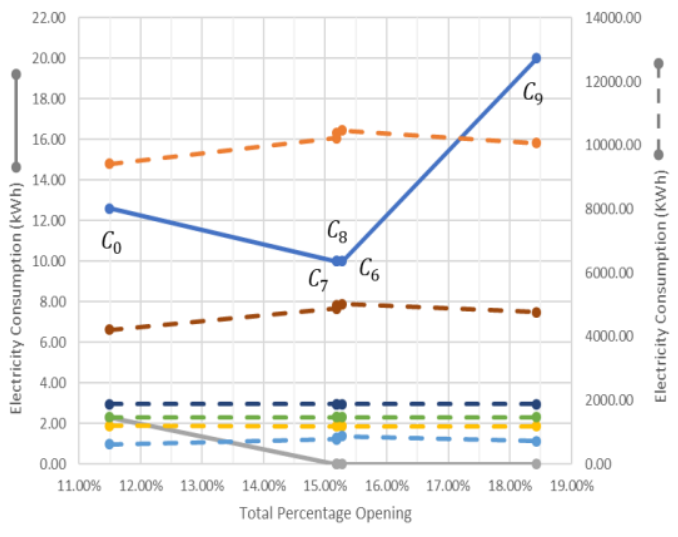

(c) Simultaneous changes in various walls

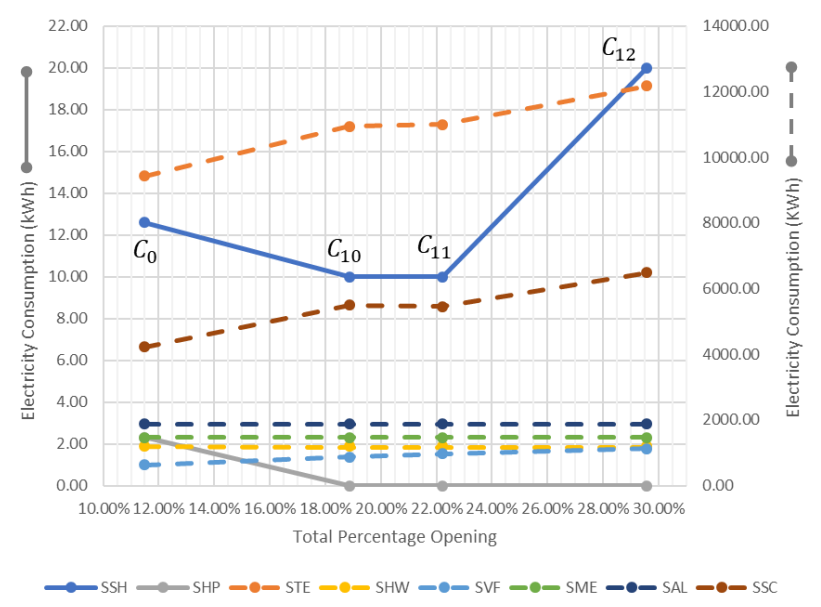

(d) Changes in South Wall

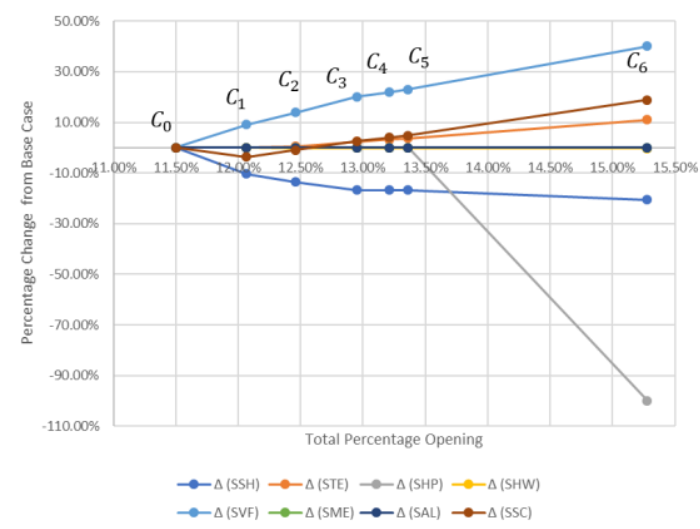

(e) Changes in Other Walls

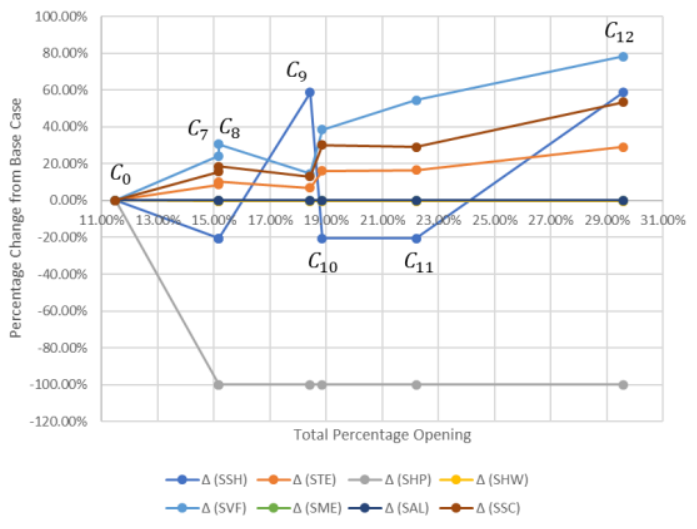

Figure 10: Graphical representation of the changes in sustainability indicators (a) for changes of openings only in the south wall, (b) for changes of openings in the 
remaining walls, (c) for simultaneous changes of opening in various walls (d) percentage change from base case for changes in the south wall (e) percentage change from base case for changes in other walls.

Table 4: Resilience Assessment Results for All Cases

\begin{tabular}{|c|c|c|c|c|c|c|c|c|}
\hline & \multicolumn{8}{|c|}{ Story Drifts } \\
\hline & \multicolumn{4}{|c|}{$\mathrm{X}$-Direction } & \multicolumn{4}{|c|}{ Y-Direction } \\
\hline $\begin{array}{c}\text { Building } \\
\text { Model }\end{array}$ & $\begin{array}{c}\text { S4 }\left(\mathbf{R}_{\mathbf{x}}^{4}\right) \\
\left(\mathbf{x 1 0} 0^{-4}\right)\end{array}$ & $\begin{array}{r}\mathbf{S 3}\left(\mathbf{R}_{\mathbf{x}}{ }^{2}\right) \\
\left(\mathbf{x 1 0 ^ { - 4 }}\right)\end{array}$ & $\begin{array}{c}\text { S2 }\left(\mathbf{R}_{x}^{2}\right) \\
\left(\mathbf{x 1 0} 0^{-4}\right)\end{array}$ & $\begin{array}{c}\text { S1 }\left(\mathbf{R}_{\mathbf{x}}{ }^{\prime}\right) \\
\left(\mathbf{x 1 0 ^ { - 4 }}\right)\end{array}$ & $\begin{array}{c}\text { S4 }\left(\mathbf{R Y}^{4}\right) \\
\left(\times 10^{-4}\right)\end{array}$ & $\begin{array}{r}\mathbf{S 3}\left(\mathbf{R Y}^{3}\right) \\
\left(\times 10^{-4}\right)\end{array}$ & $\begin{array}{c}\mathbf{S 2}\left(\mathbf{R Y}^{2}\right) \\
\left(\mathbf{x 1 0 ^ { - 4 }}\right)\end{array}$ & $\begin{array}{c}\text { S1 } \\
\left(\mathbf{R Y}^{1}\right) \\
\left(\mathbf{x 1 0}^{-4}\right)\end{array}$ \\
\hline $\mathrm{C}_{0}$ & 4.24 & 2.44 & 1.06 & 1.38 & 2.07 & 3.88 & 2.67 & 0.94 \\
\hline $\mathbf{C}_{1}$ & 4.3 & 2.48 & 1.3 & 1.39 & 2.07 & 3.9 & 2.65 & 0.94 \\
\hline $\mathbf{C}_{2}$ & 4.31 & 2.49 & 1.37 & 1.38 & 2.07 & 3.92 & 2.66 & 0.93 \\
\hline $\mathbf{C}_{3}$ & 4.32 & 2.5 & 1.56 & 1.35 & 2.08 & 3.94 & 2.66 & 0.93 \\
\hline $\mathrm{C}_{4}$ & 4.35 & 2.52 & 1.61 & 1.48 & 2.09 & 3.95 & 2.67 & 0.94 \\
\hline $\mathrm{C}_{5}$ & 4.36 & 2.53 & 1.61 & 1.6 & 2.09 & 3.95 & 2.67 & 0.94 \\
\hline $\mathrm{C}_{6}$ & 4.82 & 2.92 & 3.12 & 2.83 & 2.13 & 4.02 & 2.68 & 0.94 \\
\hline $\mathbf{C}_{7}$ & 4.32 & 2.54 & 1.06 & 1.37 & 2.23 & 4.2 & 3.28 & 1.21 \\
\hline $\mathrm{C}_{8}$ & 4.27 & 2.47 & 1.05 & 1.37 & 2.23 & 4.21 & 3.22 & 1.24 \\
\hline C9 & 4.55 & 2.68 & 1.43 & 1.59 & 2.17 & 4.04 & 2.75 & 0.91 \\
\hline $\mathrm{C}_{10}$ & 4.35 & 2.57 & 1.05 & 1.35 & 2.38 & 4.48 & 3.29 & 1.23 \\
\hline $\mathrm{C}_{11}$ & 5.11 & 3.08 & 3.03 & 2.78 & 2.25 & 4.19 & 2.75 & 0.91 \\
\hline $\mathrm{C}_{12}$ & 5.23 & 3.24 & 3.06 & 2.73 & 2.61 & 4.86 & 3.41 & 1.22 \\
\hline
\end{tabular}

** $S=$ Story, $R_{X}{ }^{N}=$ Story Drift in $X$-direction for story $N, R_{Y}^{N}=$ Story Drift in Y-direction for story $N$

Values of story drift for different stories of the building are shown in the table 4.

Figure 11 shows the graphical representation of the results of the resilience assessment (i.e. graphical representation of results shown in table 4). The graphs in figure 11 are divided based on changes of openings made in various walls. Results for changes in south wall (i.e. from $\mathrm{C}_{0}$ to $\mathrm{C}_{6}$ ) are shown in figure 11 (a). Similarly, results for changes made in other walls (i.e. from $\mathrm{C}_{7}$ to $\mathrm{C}_{9}$ ) are shown in figure 11 (b). Results for simultaneous changes in various walls (i.e. from $\mathrm{C}_{10}$ to $\mathrm{C}_{12}$ ) are shown in figure 11 (c). In addition, figure 11 (d) shows 
percentage change from base case for changes in South wall and figure 11 (e) shows percentage change from base case for changes in other walls. Results showed that for most of the cases, with additional openings, the story drift values of the building increased in both directions (i.e. direction parallel to the length of the building and direction parallel to the breadth of the building), except for story 2 and story 1 . In other words, increasing the openings made the building more vulnerable to the earthquake damages.

Results showed unusual patterns in figure 11 (e), i.e. from $\mathrm{C}_{7}$ to $\mathrm{C}_{12}$. For story drift of story 2 in Y-direction against earthquake load in Y-direction (EQy), the drift value decreased from $C_{0}$ to $C_{1}$, but it increased from $C_{1}$ to $C_{6}$. For story drift of story 1 in $X$ direction against earthquake load in X-direction (EQx), while increasing opening, drift value increased from $C_{0}$ to $C_{1}$, but it decreased from $C_{1}$ to $C_{3}$, and then again it increased from $\mathrm{C}_{3}$ to $\mathrm{C}_{6}$. For story drift of story 1 in $\mathrm{Y}$-direction against earthquake load in $\mathrm{Y}$ direction, while increasing the opening, drift value was same for all cases except for $\mathrm{C}_{2}$ and $\mathrm{C}_{3}$. This result indicates that even though highest drift values are obtained for top stories, bottom stories are also significantly impacted by changes in openings in various walls of the building. 
(a) Changes in South Wall

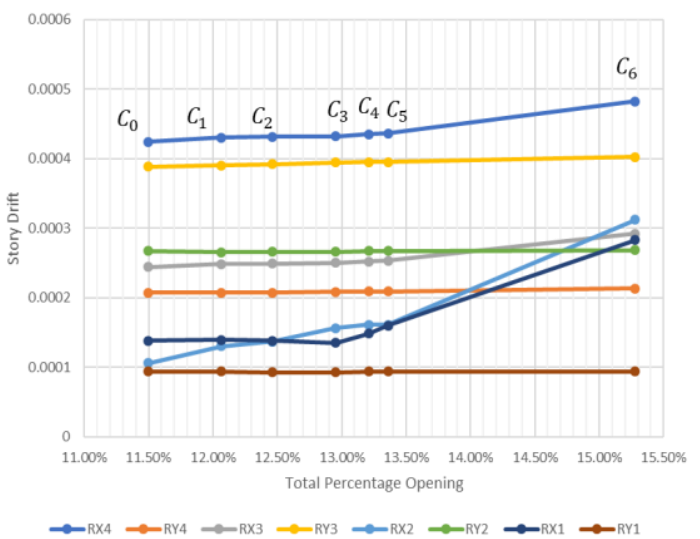

(b) Changes in remaining walls

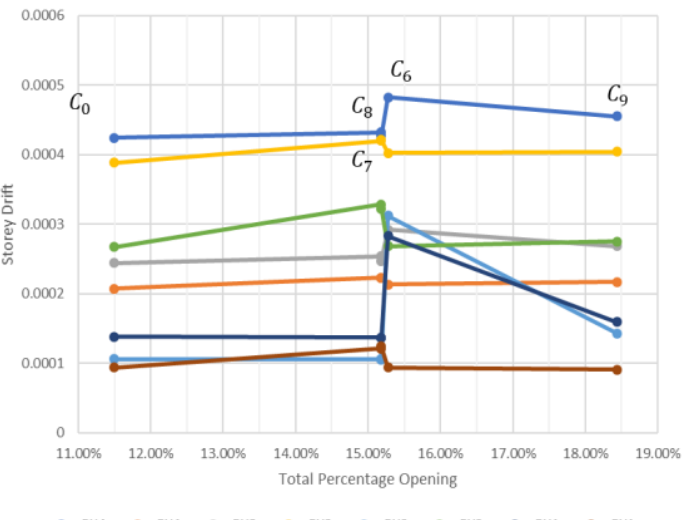

(c) Simultaneous changes in various walls

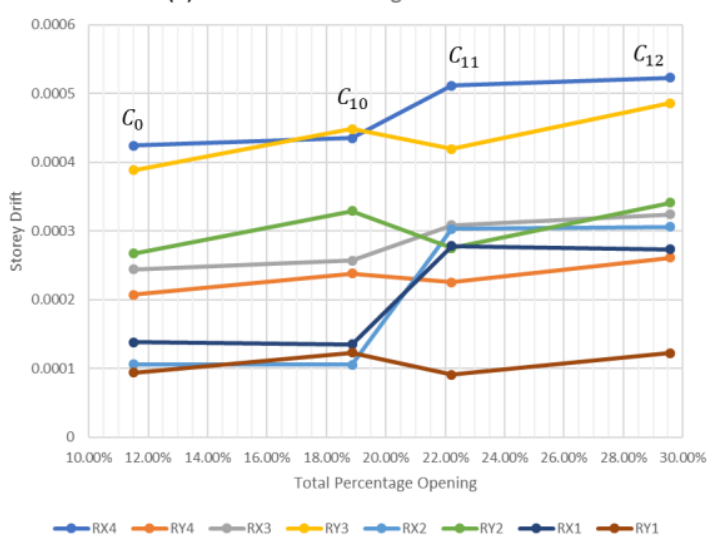

(d) Changes in South Wall

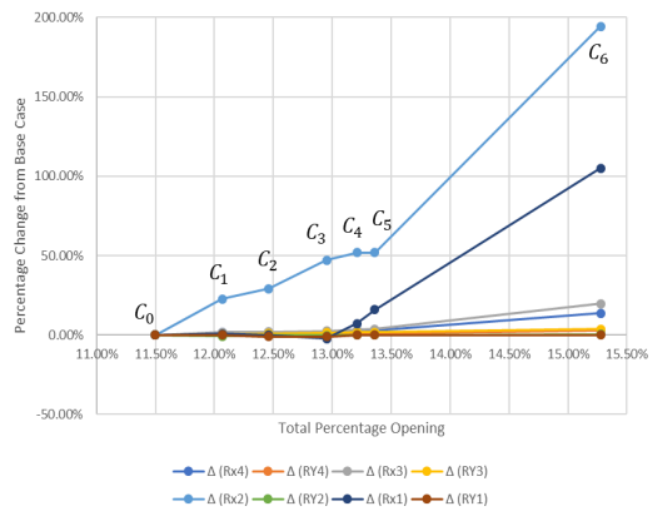

(e) Changes in Other Walls

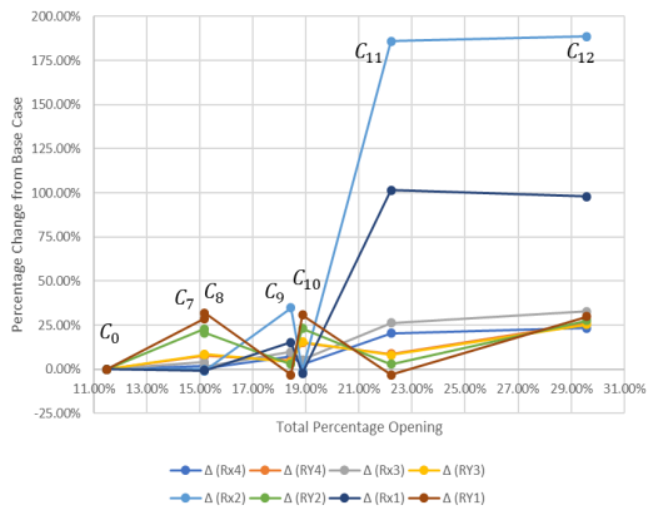

Figure 11: Graphical representation of the changes in resilience indicators (a) for changes of openings only in the south wall, (b) for changes of openings in the 
remaining walls, (c) for simultaneous changes of opening in various walls (d) percentage change from base case for changes in the south wall (e) percentage change from base case for changes in other walls

\subsection{Combined Results from Both Analyses}

The percentage change (from base case scenario) in sustainability and resilience indicators are shown below:

Table 5: Changes (\%) in Sustainability and Resilience Indicators from Base Case

\begin{tabular}{|c|c|c|c|c|c|c|c|c|c|c|c|c|c|c|c|c|}
\hline & \multicolumn{16}{|c|}{$\Delta(\%)$} \\
\hline Case & $\mathbf{S}_{\mathrm{SH}}$ & $\mathbf{S}_{\mathrm{TE}}$ & $\mathbf{S}_{\mathrm{HP}}$ & $\mathbf{S}_{\mathrm{HW}}$ & $\mathbf{S}_{\mathrm{VF}}$ & $\mathbf{S}_{\mathrm{ME}}$ & $\mathbf{S}_{\mathrm{AL}}$ & $\mathbf{S}_{\mathrm{SC}}$ & $\mathbf{R}^{4}$ & $\mathbf{R}_{\mathbf{Y}}{ }^{4}$ & $\mathbf{R x}^{3}$ & $\mathbf{R}_{\mathbf{Y}}{ }^{3}$ & $\mathbf{R x}^{2}$ & $\mathbf{R}_{\mathbf{Y}}{ }^{2}$ & $\mathbf{R}_{\mathbf{x}}{ }^{1}$ & $\mathbf{R}_{\mathbf{Y}}{ }^{1}$ \\
\hline $\mathrm{C}_{0}$ & 0.00 & 0.00 & 0.00 & 0.00 & 0.00 & 0.00 & 0.00 & 0.00 & 0.00 & 0.00 & 0.00 & 0.00 & 0.00 & 0.00 & 0.00 & 0.00 \\
\hline $\mathrm{C}_{1}$ & -10.32 & 0.00 & 0.00 & -0.04 & 9.19 & 0.00 & 0.00 & -3.68 & 1.42 & 0.00 & 1.64 & 0.52 & 22.64 & -0.75 & 0.72 & 0.00 \\
\hline $\mathrm{C}_{2}$ & -13.49 & 0.49 & 0.00 & -0.06 & 13.90 & 0.00 & 0.00 & -0.91 & 1.65 & 0.00 & 2.05 & 1.03 & 29.25 & -0.37 & 0.00 & -1.06 \\
\hline $\mathrm{C}_{3}$ & -16.67 & 2.48 & 0.00 & -0.08 & 20.13 & 0.00 & 0.00 & 2.62 & 1.89 & 0.48 & 2.46 & 1.55 & 47.17 & -0.37 & -2.17 & -1.06 \\
\hline $\mathrm{C}_{4}$ & -16.67 & 3.21 & 0.00 & -0.11 & 21.89 & 0.00 & 0.00 & 4.00 & 2.59 & 0.97 & 3.28 & 1.80 & 51.89 & 0.00 & 7.25 & 0.00 \\
\hline $\mathrm{C}_{5}$ & -16.67 & 3.65 & 0.00 & -0.12 & 22.95 & 0.00 & 0.00 & 4.82 & 2.83 & 0.97 & 3.69 & 1.80 & 51.89 & 0.00 & 15.94 & 0.00 \\
\hline $\mathrm{C}_{6}$ & -20.63 & 11.11 & -100.00 & -0.32 & 40.13 & 0.00 & 0.00 & 18.88 & 13.68 & 2.90 & 19.67 & 3.61 & 194.34 & 0.37 & 105.07 & 0.00 \\
\hline $\mathbf{C}_{7}$ & -20.63 & 8.56 & -100.00 & -0.32 & 24.20 & 0.00 & 0.00 & 15.57 & 1.89 & 7.73 & 4.10 & 8.25 & 0.00 & 22.85 & $\begin{array}{l}-0.72 \\
\end{array}$ & 28.72 \\
\hline $\mathrm{C}_{8}$ & -20.63 & 10.26 & -100.00 & -0.32 & 30.57 & 0.00 & 0.00 & 18.41 & 0.71 & 7.73 & 1.23 & 8.51 & -0.94 & 20.60 & -0.72 & 31.91 \\
\hline $\mathrm{C}_{9}$ & 58.73 & 6.86 & -100.00 & -0.32 & 14.65 & 0.00 & 0.00 & 12.96 & 7.31 & 4.83 & 9.84 & 4.12 & 34.91 & 3.00 & 15.22 & -3.19 \\
\hline $\mathrm{C}_{10}$ & -20.63 & 16.10 & -100.00 & -0.32 & 38.54 & 0.00 & 0.00 & 30.25 & 2.59 & 14.98 & 5.33 & 15.46 & $\begin{array}{l}-0.94 \\
\end{array}$ & 23.22 & $\begin{array}{l}-2.17 \\
\end{array}$ & 30.85 \\
\hline $\mathrm{C}_{11}$ & -20.63 & 16.63 & -100.00 & -0.32 & 54.46 & 0.00 & 0.00 & 29.07 & 20.52 & 8.70 & 26.23 & 7.99 & 185.85 & 3.00 & 101.45 & -3.19 \\
\hline $\mathrm{C}_{12}$ & 58.73 & 29.15 & -100.00 & -0.32 & 78.34 & 0.00 & 0.00 & 53.46 & 23.35 & 26.09 & 32.79 & 25.26 & 188.68 & 27.72 & 97.83 & 29.79 \\
\hline
\end{tabular}

The main goal of this study is to analyze how the changes in opening of the building affects the sustainability and resilience indicators. So, a combined graph is plotted (as shown in figure 12) to observe the variation in values of each indicators (from base case values) for each case scenarios.

Figure 12 shows the pattern of variation of all indicators (from both analysis) with respect to base case scenario, while increasing the opening of the building. In both figure 12 (a) and (b) graphs, percentage change in value of each indicator from base case scenario 
is plotted in $\mathrm{Y}$-axis and total percentage opening of the building is plotted in $\mathrm{X}$-axis. Both graphs are formatted in the same way: with transparent red color indicating percentage variation for resilience indicators and green color indicating the percentage variation for sustainability indicators. Figure 12 (a) shows the percentage variation in results of all indicators for first six cases with respect to base case (i.e. from $\mathrm{C}_{0}$ to $\mathrm{C}_{6}$ ), when the changes in openings are made only on the south wall. From $\mathrm{C}_{0}$ to $\mathrm{C}_{6}$, for resilience indicators, highest variations were observed for change in story drift of story 2 in X-direction and change in story drift of story 1 in X-direction. Similarly, for the same cases for sustainability indicators, the highest variations were observed for change in electricity consumption for: ventilation fan, heat pump supply and space heating. Values of all other indicators were in similar range with respect to base case scenario. This result infers that even the changes made in openings of a single wall can make a significant impact in some of the sustainability and resilience indicators while some other indicators are not affected at all.

In addition, for graph figure 12 (b), shows the percentage variation in results of all indicators for last six cases (i.e. $C_{7}$ to $C_{12}$ ), with respect to $C_{0}$. From $C_{7}$ to $C_{12}$, the highest percentage change in values of resilience indicators were observed for story drift of story 2 in X-direction and story drift of story 1 in X-direction. This result indicates the impact of changes in opening in the structural integrity (i.e. robustness) of an unreinforced masonry building. For sustainability indicators, the highest variations were observed for change in electricity consumption for: ventilation Fan, heat pump supply, space heating and space cooling. This result infers that the changes made in openings of different walls can 
significantly and simultaneously affect some sustainability and resilience indicators while some other indicators are indifferent to such changes.

(a) Changes in South Wall

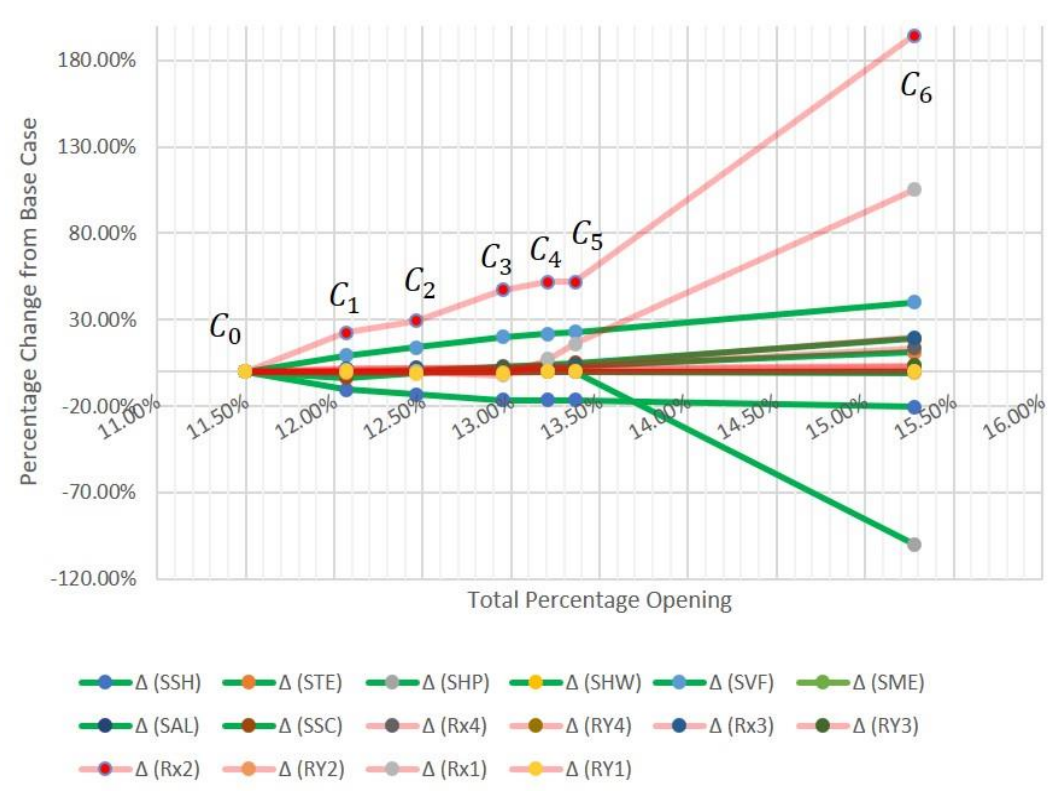

(b) Changes in Other Walls

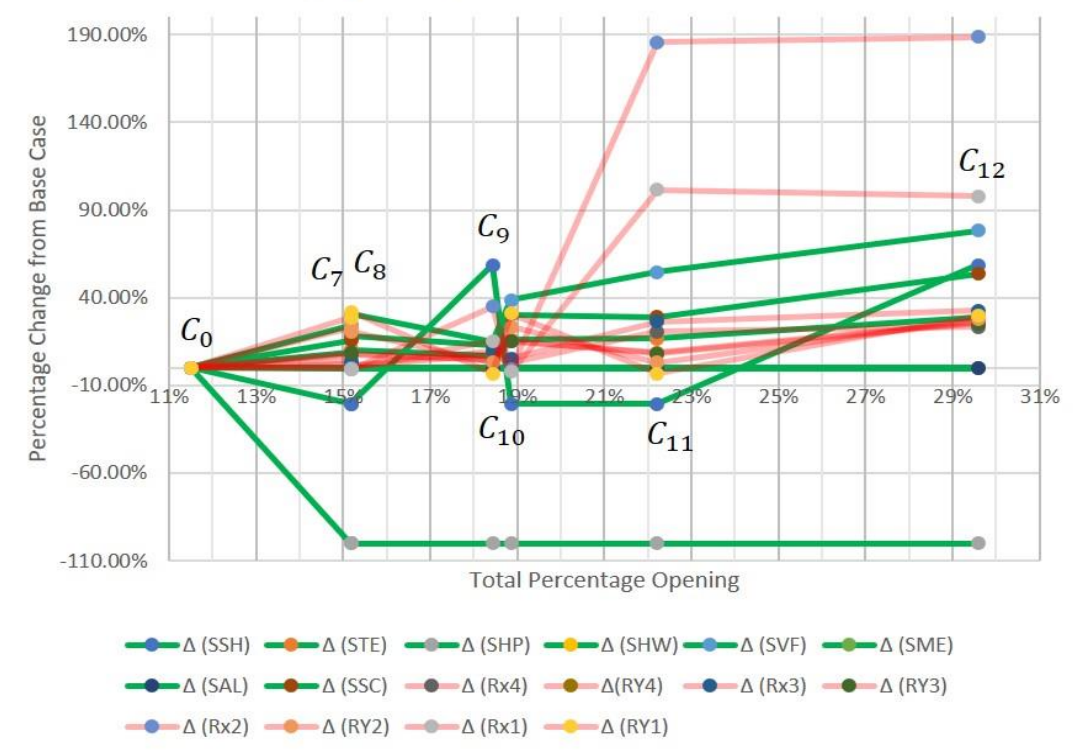

Figure 12: Concurrent changes in sustainability and resilience indicators with respect to base case 
Correlation of total percentage opening with sustainability and resilience indicators are shown in table 6.

Table 6: Correlation between opening and each indicator from both analyses

\begin{tabular}{|c|c|c|c|c|c|c|c|c|c|c|c|c|c|c|c|c|}
\hline \multirow{3}{*}{ Correlation } & \multirow{2}{*}{\multicolumn{8}{|c|}{$\begin{array}{l}\text { Annual Electricity Consumption for different activities } \\
\qquad(\mathrm{kWh})\end{array}$}} & \multicolumn{8}{|c|}{ Story Drift in } \\
\hline & & & & & & & & & \multicolumn{4}{|c|}{ X-Direction } & \multicolumn{4}{|c|}{ Y-Direction } \\
\hline & SsH & $\mathbf{S}_{\text {TE }}$ & SHP & SHW & SvF $_{\text {V }}$ & $\mathbf{S}_{\mathrm{ME}}$ & $\mathbf{S}_{\mathrm{AL}}$ & Ssc & $\begin{array}{c}\mathbf{S 4} \\
\left(\mathbf{R x}^{4}\right)\end{array}$ & $\begin{array}{c}\mathbf{S 3} \\
\left(\mathbf{R x}^{3}\right)\end{array}$ & $\begin{array}{c}\mathbf{S 2} \\
\left(\mathbf{R x}^{2}\right)\end{array}$ & $\begin{array}{c}\mathbf{S 1} \\
\left(\mathbf{R x}^{1}\right)\end{array}$ & $\begin{array}{c}\mathbf{S 4} \\
\left(\mathbf{R Y}_{\mathbf{Y}}{ }^{4}\right)\end{array}$ & $\begin{array}{c}\mathbf{S 3} \\
\left(\mathbf{R Y}^{3}\right)\end{array}$ & $\begin{array}{c}\mathbf{S 2} \\
\left(\mathbf{R Y}^{2}\right)\end{array}$ & $\begin{array}{c}\text { S1 } \\
\left(\mathbf{R}_{\mathbf{Y}}{ }^{1}\right)\end{array}$ \\
\hline $\begin{array}{c}\text { Total } \\
\text { Percentage } \\
\text { Opening } \\
\text { (Changes in } \\
\text { South wall) }\end{array}$ & $\begin{array}{c}- \\
0.84\end{array}$ & 0.97 & $\begin{array}{c}- \\
0.84\end{array}$ & $\begin{array}{c}- \\
0.99\end{array}$ & 0.99 & 0.00 & 0.00 & 0.94 & 0.93 & 0.92 & 0.96 & 0.88 & 0.96 & 0.99 & 0.66 & 0.15 \\
\hline $\begin{array}{c}\text { Total } \\
\text { Percentage } \\
\text { Opening } \\
\text { (Changes in } \\
\text { Other } \\
\text { walls) }\end{array}$ & 0.52 & 0.95 & $\begin{array}{c}- \\
0.54\end{array}$ & $\begin{array}{c}- \\
0.54\end{array}$ & 0.93 & 0.00 & 0.00 & 0.94 & 0.91 & 0.94 & 0.86 & 0.84 & 0.88 & 0.84 & 0.39 & 0.17 \\
\hline
\end{tabular}

$* * S N=$ Story $N, S_{X X}=$ Sustainability value for indicator $X X$

Correlation between sustainability and resilience indicators are shown in Table 7.

Table 7: Correlation between each sustainability and resilience indicator

\begin{tabular}{|c|c|c|c|c|c|c|c|c|c|c|c|c|c|c|c|c|}
\hline \multirow{4}{*}{ Correlation } & \multicolumn{16}{|c|}{ Story Drift for } \\
\hline & \multicolumn{8}{|c|}{ Changes in South Wall } & \multicolumn{8}{|c|}{ Changes in Other Walls } \\
\hline & \multicolumn{4}{|c|}{ X-Direction } & \multicolumn{4}{|c|}{ Y-Direction } & \multicolumn{4}{|c|}{ X-Direction } & \multicolumn{4}{|c|}{ Y-Direction } \\
\hline & $\mathbf{R}_{\mathbf{X}}{ }^{4}$ & $\mathbf{R}_{\mathbf{X}}{ }^{3}$ & $\mathbf{R}_{\mathbf{X}}^{2}$ & $\mathbf{R}_{\mathbf{X}}{ }^{1}$ & $\mathbf{R}_{\mathbf{Y}}{ }^{4}$ & $\mathbf{R}_{\mathbf{Y}}{ }^{3}$ & $\mathbf{R}_{\mathbf{Y}}{ }^{2}$ & $\mathbf{R}_{\mathbf{Y}}^{1}$ & $\mathbf{R}_{\mathbf{X}}{ }^{4}$ & $\mathbf{R}_{\mathbf{X}}{ }^{3}$ & $\mathbf{R}_{\mathbf{X}}^{2}$ & $\mathbf{R}_{\mathbf{x}}{ }^{1}$ & $\mathbf{R}_{\mathbf{Y}}{ }^{4}$ & $\mathbf{R}_{\mathbf{Y}}{ }^{3}$ & $\overline{\mathbf{R}_{\mathrm{Y}}^{2}}$ & $\mathbf{R}_{\mathbf{Y}}^{1}$ \\
\hline $\mathbf{S}_{\mathrm{SH}}$ & 0.62 & 0.61 & 0.70 & 0.52 & 0.67 & 0.86 & 0.26 & 0.16 & 0.45 & 0.46 & 0.36 & 0.33 & 0.35 & 0.30 & 0.05 & 0.21 \\
\hline $\mathbf{S}_{\mathrm{TE}}$ & 0.97 & 0.97 & 0.98 & 0.95 & 0.99 & 0.96 & 0.75 & 0.26 & 0.79 & 0.83 & 0.75 & 0.73 & 0.96 & 0.95 & 0.62 & 0.44 \\
\hline $\mathbf{S}_{\mathrm{HP}}$ & 0.98 & 0.98 & 0.96 & 0.99 & 0.91 & 0.81 & 0.65 & $-\overline{26}$ & $\begin{array}{c}- \\
0.36\end{array}$ & $\begin{array}{c}- \\
0.39\end{array}$ & $\begin{array}{c}- \\
0.29\end{array}$ & $\overline{0}-\overline{28}$ & 0.53 & 0.53 & 0.54 & $\overline{0.42}$ \\
\hline $\mathbf{S}_{\mathrm{HW}}$ & $\begin{array}{c}- \\
0.97\end{array}$ & $\begin{array}{c}- \\
0.97\end{array}$ & $0 . \overline{99}$ & $\begin{array}{c}- \\
0.95\end{array}$ & 0.98 & $\begin{array}{c}- \\
0.97\end{array}$ & $\begin{array}{c}- \\
0.68\end{array}$ & $\begin{array}{c}- \\
0.23\end{array}$ & $\begin{array}{c}- \\
0.36\end{array}$ & $\begin{array}{c}- \\
0.39\end{array}$ & $\begin{array}{c}- \\
0.29\end{array}$ & $\begin{array}{c}- \\
0.28\end{array}$ & $\begin{array}{c}- \\
0.53\end{array}$ & 0.53 & $\begin{array}{c}- \\
0.54\end{array}$ & $\begin{array}{c}- \\
0.42\end{array}$ \\
\hline $\mathbf{S}_{\mathrm{VF}}$ & 0.87 & 0.86 & 0.92 & 0.81 & 0.92 & 0.99 & 0.58 & 0.07 & 0.84 & 0.87 & 0.82 & 0.81 & 0.90 & 0.89 & 0.55 & 0.38 \\
\hline $\mathbf{S}_{\mathrm{ME}}$ & 0.00 & 0.00 & 0.00 & 0.00 & 0.00 & 0.00 & 0.00 & 0.00 & 0.00 & 0.00 & 0.00 & 0.00 & 0.00 & 0.00 & 0.00 & 0.00 \\
\hline $\mathbf{S}_{\mathrm{AL}}$ & 0.00 & 0.00 & 0.00 & 0.00 & 0.00 & 0.00 & 0.00 & 0.00 & 0.00 & 0.00 & 0.00 & 0.00 & 0.00 & 0.00 & 0.00 & 0.00 \\
\hline $\mathbf{S}_{\mathbf{S C}}$ & 0.95 & 0.95 & 0.96 & 0.95 & 0.99 & 0.93 & 0.83 & 0.26 & 0.78 & 0.82 & 0.73 & 0.71 & 0.97 & 0.96 & 0.63 & 0.45 \\
\hline
\end{tabular}

$* * S_{X X}=$ Sustainability value for indicator $X X, R_{X}{ }^{N}=$ Story drift for story $N$ in $X$-direction, $R_{Y}^{N}=$ Story drift for story $N$ in $Y$-direction, 
Table 6 shows the highest correlation between total percentage opening and sustainability indicator as 0.99 , which is the correlation between total percentage opening and electricity consumption for ventilation fans. It means the more openings the building has, higher will be the electricity consumption for ventilation fans. The highest correlation between total percentage opening and resilience indicator is 0.99 , which is the correlation between total percentage opening and story drift in Y-direction for story 3. This correlation indicates that while increasing the opening of the building, story drift of story 3 in $\mathrm{Y}$ direction increases significantly, making the building more vulnerable. Some of the indicators are highly negatively correlated. For example, for changes in south wall, correlation between electricity consumption for space heating and story drift of story 3 in Y-direction is -0.86 . Such highly negative correlations are obtained because electricity consumption for space heating is decreasing by a considerable margin while story drift is increasing. Also, as the openings are increased, the building will have more exposure to the sunlight and will require less space heating work. In addition, story drift is increasing significantly as more openings will decrease the structural integrity of walls for unreinforced masonry buildings. Some indicators are highly negatively correlated as the changes in openings significantly increase values of resilience indicators, while simultaneously decreasing the values of sustainability indicators and vice-versa.

Moreover, table 7 shows the correlation between sustainability and resilience indicators for changes in south wall and for changes in other walls. Highly positive correlations are shown in dark green color and low positive correlations are shown in light green color. Highly negative correlations are shown in dark red and low negative correlations are shown in light red color. Silver color is used to indicate no correlation (i.e. 
correlation value equals to zero). Some indicators are highly positively correlated which means such indicators reinforce each other. For example: for changes in south wall, correlation between electricity consumption for ventilation fans and story drift of story 3 in Y-direction is 0.99 . Also, correlation between total electricity consumption and story drift of story 4 in Y-direction is 0.99 . For changes in other walls, table 7 shows highest positive correlation between electricity consumption for space cooling and story drift of story 4 in Y-direction (0.97). In addition, some indicators are highly negatively correlated which means such indicators undermine each other. For example: for changes in south wall, correlation between electricity consumption for hot water and story drift in Xdirection for story 2 is -0.99 . Similarly, correlation between electricity consumption between heat pump supply and story drift in X-direction for story 1 is also -0.99 . For changes in other walls, correlation between electricity consumption between heat pump supply and story drift in Y-direction for story 2 is -0.54 .

Indicators having the highly positive and highly negative correlation values indicate that designers and stakeholders should give thorough attention to such indicators while designing a building. As such indicators might significantly enhance or weaken each other, their correlation will have a critical impact in deciding the final design parameters of a building. Table 7 also indicates that correlation between such indicators are critical (i.e. higher values) when changes are made in the same wall rather than when changes are made in different walls. For example: in table 7, most of the observed correlation values are higher for changes within south wall than correlation values for changes in different walls. 


\subsection{Discussion of Results}

Few existing studies have explored the unification of sustainability and resilience of different civil infrastructure systems. For example, Bocchini et al. applied an integrated perspective for analysis of resilience and sustainability of a bridge [6]. They highlighted that resilience and sustainability are complimentary and should be given equal priority while designing an infrastructure [6]. Similarly, Roostaie et al. emphasized creating a comprehensive structure for sustainability and resilience in order to achieve enhanced resilience at minimal environmental impact [7]. They concluded that the unification process needs an establishment of a new integrated assessment method or a detailed enhancement of existing frameworks [7].

Unification of sustainability and resilience of a building is a relatively new area of research. A framework that can effectively unify sustainability and resilience of a building is yet to be established and is a challenging task for scholars [3, 5-7]. In case of buildings, most of the available literature have analyzed sustainability and resilience separately and not in an integrated perspective. For example, Yuksel et al. studied the electric energy efficiency of residential houses in a hot climate based on openings and roof type provided [50]. They highlighted that the application of passive solar design strategies on openings along with green roof, enhanced annual overall energy performance by 48\% [50]. Similarly, Lai et al. studied the electric energy saving potential of the building envelope design (like openings) in residential houses [51]. They concluded that having control over the dominant factors in the building envelope is indeed an important step in the path to achieving energy savings in residential houses [51]. Moreover, Parisi et al. studied the seismic capacity of an unreinforced masonry wall and its relationship with the irregular 
openings [52]. They revealed that irregular openings decrease resilience of the walls (i.e. significantly reduces the capacity of the wall to withstand lateral loads) [52]. Similarly, Yi et al. studied the behavior and highlighted the vulnerability of unreinforced masonry buildings against lateral loads [53].

The methodology proposed in this study is a novel framework for the unification of sustainability and resilience of an unreinforced masonry building. Existing literature have analyzed sustainability and resilience of a building system separately and not with an integrated perspective. Especially for an unreinforced masonry building, existing literature have not analyzed the unification of sustainability and resilience. Therefore, the framework used in this study is different from the existing ones, because it uses an integrated perspective to analyze sustainability and resilience of an unreinforced masonry building. In this study, the sustainability assessment results show that with additional openings in an unreinforced masonry building, the total electricity energy consumption increases. This result aligns with the conclusion of Yuksel et el. and Lai et al., because they concluded that the building envelope design significantly impacts the electricity energy consumption of the building $[50,51]$. Similarly, the results from the resilience assessment of this study show a decrease in resilience (i.e. increase in story drift of different floors) with additional openings. This result aligns with the conclusion of Parisi et al. and Yi et al., because these studies also concluded that the vulnerability of an unreinforced masonry wall increases with the increase in openings [52,53].

To summarize, the unification of sustainability and resilience is a relatively new concept in the literature, specifically in building design and construction. The main 
knowledge gap in the existing literature is the lack of a single effective methodology to unify the concept of sustainability and resilience. Therefore, this study developed a novel approach for the integration of sustainability and resilience of building systems. The results obtained from both analyses quantified sustainability indicators such as electric energy consumption as well as story drifts for resilience (i.e. robustness). Specifically, the results obtained in this study can be useful for unreinforced masonry buildings in a tropical climate. If the building analyzed in this study was located in a cold climate region, the results would have varied for sustainability assessment. To be specific, space heating electricity consumption would have increased, and space cooling electricity consumption would have decreased significantly.

In addition, this study presented infographics of changes in the results of sustainability and resilience indicators. Their correlations were observed while changing available openings in different masonry walls. Results show that there is a negative correlation between space heating and percentage opening for cases from $\mathrm{C}_{0}$ to $\mathrm{C}_{6}$, but the same does not hold true for cases from $\mathrm{C}_{7}$ to $\mathrm{C}_{12}$. Results indicates the level of unpredictability while dealing with such indicators. In addition, it is observed that there is a positive correlation between story drift and percentage opening. Moreover, another point to be noted from this result is that the same decision (i.e. changing opening) can lead to an increase in the sustainability of the building (i.e. less electricity consumption for space heating purpose from $\mathrm{C}_{0}$ to $\mathrm{C}_{6}$ ), while simultaneously decreasing the resilience of the same building (i.e. increase in story drift value from $\mathrm{C}_{0}$ to $\mathrm{C}_{6}$ ). 
Results obtained from sustainability analysis, as shown in figure 10, indicate that the more openings the building has, the less will be the electricity consumption for space heating up to a certain level. However, beyond that certain level it can change positively and negatively or remain constant based on other factors like location of the opening. Moreover, with additional openings, total electricity consumption required to operate the building will be increased because of the increase in electricity consumption for other activities such as space cooling and ventilation fans. Results show that the total electricity consumption of the building is increased when openings are increased, which means the overall sustainability value of the building is decreased. But, at the same time, electricity consumption for space heating is decreasing (for the most part) when openings are increasing, which means sustainability value is increasing with respect to space heating consumption. All results obtained from sustainability assessment indicate that electricity consumption for all other activities in the building are either constant or keep increasing, except for electricity consumption for space heating purpose.

In figure 11, the results from resilience assessment are plotted in a graphical format. The results show that with increase in openings for most of the cases, story drift value of an unreinforced masonry building keeps on increasing in both directions (i.e. direction parallel to the length and direction parallel to breadth of the building) for all stories. This result infers that with more openings, an unreinforced masonry building becomes more vulnerable with respect to its capacity to deal with the earthquake lateral load. Moreover, from figure 12, it can be inferred that the percentage change in values of various indicators (with respect to base case scenario) is significantly impacted by openings and their location. For example, even when $\mathrm{C}_{7}$ (changes in East wall) and $\mathrm{C}_{8}$ (changes in West wall) 
have the same total opening (i.e. 15.18\%), the percentage change in electricity consumption for ventilation fans (with respect to base case) is higher for $\mathrm{C}_{8}$ by $6.37 \%$. In addition, for the same cases (i.e. $\mathrm{C}_{7}$ and $\mathrm{C}_{8}$ ), percentage change in story drift (with respect to base case scenario) of story 1 in $\mathrm{Y}$-direction is higher for $\mathrm{C}_{8}$ by $3.19 \%$. This comparison shows that the value of total percentage opening is not the only factor affecting sustainability and resilience indicators of a building. Instead, there are other factors such as location of changes in openings, which also contribute to determine the value of such indicators.

To find the optimal value of total percentage opening based on results obtained from both assessments, the results of the first six cases are analyzed, as results for the last six cases are not as uniform. The relationship between two parameters is considered for the analysis: space heating electricity consumption and story drift of story 4 in x-direction. These two parameters are selected because they undermine each other and have negative correlation. Linear regression is used to establish mathematical relationship (equation) between: i) total percentage opening vs space heating electricity consumption and ii) total percentage opening vs story drift of story 4 in x-direction. Equations thus obtained are subjected to certain constraints, as stakeholders will have certain constraints while deciding a design parameter. Linear optimization method is used to simplify the approach. Two sets of constraints are assumed and used to demonstrate the optimal opening calculation. Details of the optimization are as follows:

Total percentage opening of the building $=\mathbf{X}$

Space heating electricity consumption $=\mathbf{Y}$

Story drift of story 4 in $\mathrm{x}$-direction $=\mathbf{Z}$ 
Mathematical relationship (or equations) obtained from linear regression:

$Z=0.0000143 * X+0.0002439$

$Y=-0.5641 * X+18.554$

\section{Decision variable: $\mathbf{X}$}

\section{Set objective: to minimize $Z$}

For constraints set $\mathbf{1}$, constraints are assumed to be as follows:

$\mathrm{X} \geq 0, \mathrm{Y} \geq 0, \mathrm{Z} \geq 0, \mathrm{Y} \leq \mathbf{1 0} \mathbf{k W h}$

For constraints set 2, constraints are assumed to be as follows:

$\mathrm{X} \geq 0, \mathrm{Y} \geq 0, \mathrm{Z} \geq 0, \mathrm{Y} \leq \mathbf{1 5} \mathbf{k W h}$

Results obtained from the optimization:

Table 8: Optimization results for different sets of constraints

\begin{tabular}{|c|c|c|c|}
\hline \multicolumn{2}{|c|}{ Optimization Results } & $\begin{array}{c}\text { Constraint Set } \\
\mathbf{1}\end{array}$ & $\begin{array}{c}\text { Constraint Set } \\
\mathbf{2}\end{array}$ \\
\hline $\begin{array}{c}\text { Story Drift of Story 4 in } \mathrm{X}- \\
\text { direction }\left(\mathrm{Rx}^{4}\right)\end{array}$ & $\mathrm{Z}$ & 0.000461 & 0.000334 \\
\hline Total Percentage Opening & $\mathrm{X}$ & $\mathbf{1 5 . 1 6 \%}$ & $\mathbf{6 . 3 \%}$ \\
\hline $\begin{array}{c}\text { Space Heating Electricity } \\
\text { Consumption }\left(\mathrm{S}_{\mathrm{SH}}\right)\end{array}$ & $\mathrm{Y}$ & $10 \mathrm{kWh}$ & $15 \mathrm{kWh}$ \\
\hline
\end{tabular}

From the results shown in table 8 , it can be concluded that the optimal opening value changes with the changes in values of the constraints. Assuming the constraint set 1 , the optimal opening value is obtained as $15.16 \%$ for the building. Similarly, assuming the constraint set 2, optimal opening value is obtained as $6.3 \%$ for the building. Therefore, 
based on assumptions and constraints used by the stakeholders for optimization, the optimal opening value of the building will change. Using such simplified optimization approach on the experimental results obtained from the sustainability and resilience assessments, stakeholders can finalize optimal value or optimal range for different design parameters of a building.

Additionally, assuming linear relationship between opening and space heating electricity consumption as well as opening and story drift of story 4 in $\mathrm{x}$-direction, a graph is plotted using the results obtained from both assessments for Base Case to Case 6. The obtained graph is shown below in figure 13 . 
Figure 13: Graph of Opening vs $\mathrm{S}_{S H}$ and Opening vs $\mathrm{Rx}^{4}$ for Base Case to Case 6

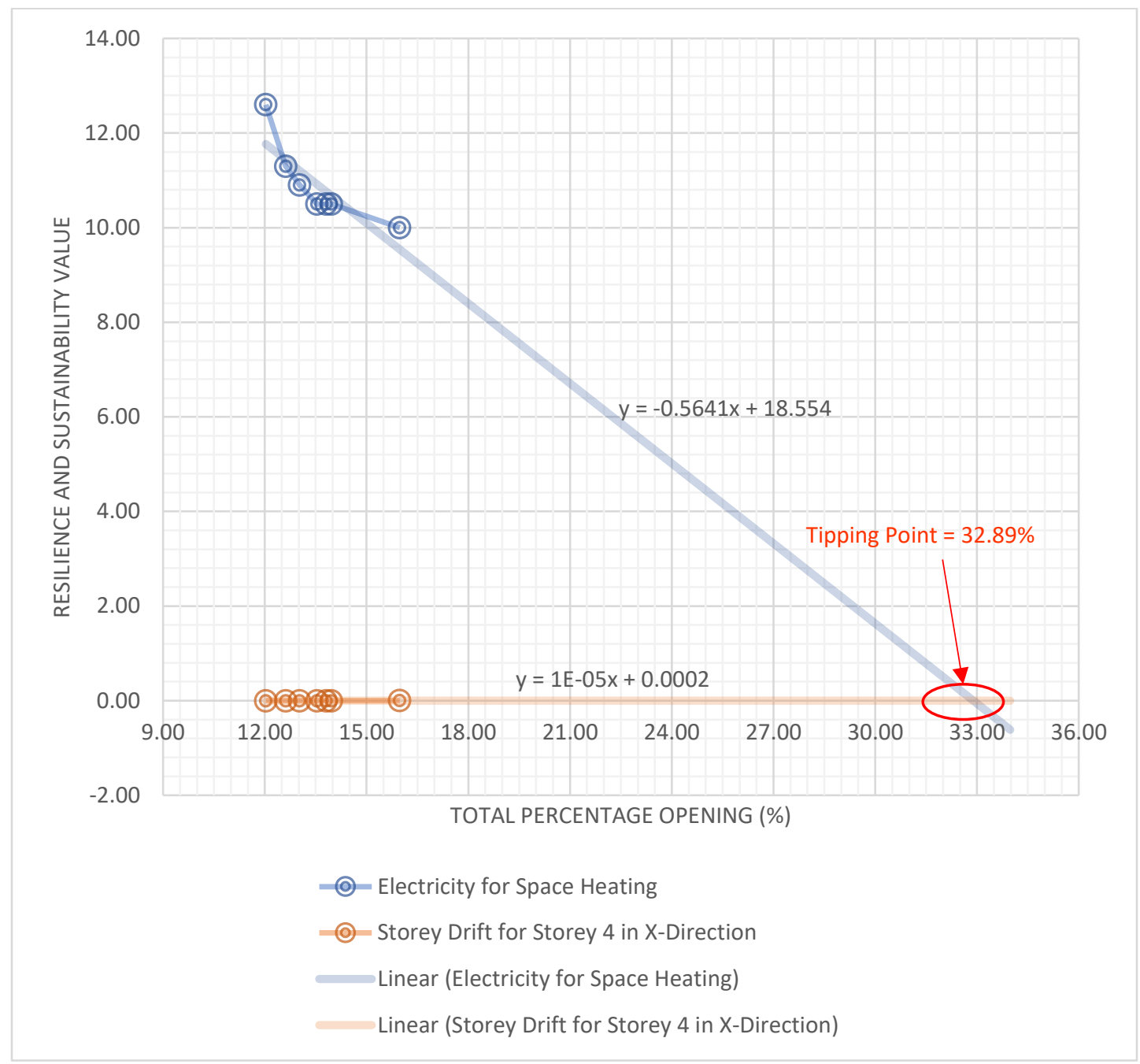

As shown in figure 13, $\mathrm{x}$-coordinate of the point of intersection between the two graphs (linear approximation line) is $32.89 \%$. The tipping point is where the values of two parameters are merging and beyond which they are starting to diverge. Even though the value of opening at tipping point seems far stretched, such type of graphical representation can help in identifying the approximate tipping points.

Such analyses will help stakeholders visualize and better understand the correlation of different sustainability and resilience indicators of a building, assisting them to make 
the building both sustainable as well as resilient. The novel framework used in this research, consisting of analyses, quantification, observation and comparison of variation in sustainability and resilience indicators, can also be used with a similar approach to help analyze different design parameters for various other civil infrastructures. Currently, such unifying notion is gaining significant attention from associated stakeholders in the construction industry. Therefore, this study can help in further analyzing this unifying notion from a novel perspective. 


\section{CHAPTER IV \\ CONCLUSION}

\subsection{Key Findings}

Sustainability and resilience are two key aspects of any infrastructure system focusing on identical goals of sustaining the infrastructure for a longer life span; however, those need to be considered throughout the expected life span starting from planning to design, construction, operations and maintenance. Moreover, unifying sustainability and resilience is even more challenging since they can reinforce or undermine each other, and careful assessments are required while exploring the different phases of infrastructure life cycle. For example, if sustainability indicators can reinforce those associated with resilience, infrastructures may experience enhanced ability to withstand external shocks such as natural disasters compared to an ordinary infrastructure. In addition, such infrastructure will also experience a longer lifespan, making it more sustainable i.e. requiring less resource consumption and reduced cost of replacement. There have been very limited studies approaching such unifying notion which is quite challenging to accomplish and observe in practice. However, it provides promising research opportunities to establish novel analytical frameworks to quantify and unify both aspects. Establishing such a framework requires identifying critical indicators concerning both sustainability and resilience, qualitative assessments of which have the major focus in the empirical literature.

This study contributes along these lines of research by establishing an experimental framework to quantify and assess structural masonry systems. In particular, this study performed energy simulation for sustainability assessment and structural analysis for resilience assessment of masonry buildings. With respect to the availability of openings in 
masonry walls, the study observed the changes in sustainability indicators such as space heating, total electricity, heat pump supply, hot water, ventilation fans, area lights and miscellaneous equipment. Likewise, changes in resilience indicators (i.e. story drifts in each floor both in $\mathrm{X}$ and $\mathrm{Y}$ direction) were also observed.

Key findings include:

- Individual assessments of sustainability indicators showed that the overall sustainability is compromised (i.e. increase in total electricity consumption) with additional openings in most of the cases, and the design becomes more expensive when increasing the size of openings because of higher electricity consumption. However, some exceptional cases include space heating and heat pump supply.

- Sustainability indicators, such as electricity consumption for space heating, could make the design more economical for additional openings in a given wall (south wall); however, such effects are not as uniform when further openings are added to other remaining walls (for example: increase in electricity consumption for space heating when openings are increased in the north side).

- Individual assessments of resilience indicators showed larger story drifts along the directions where changes are being made, with additional openings making such unreinforced masonry systems more vulnerable to external shocks (i.e. less robustness).

- Differential effects were observed when concurrent assessments were made on sustainability and resilience indicators. For example, a small change in one design parameter such as openings (i.e. windows and/or doors) in masonry walls can 
concurrently change sustainability indicators such as electric energy consumption and resilience indicators such as story drifts.

- Correlations between the changes in different sustainability and resilience indicators are also important. They can be positive or negative as well as high, medium or low. For example, for changes in the south wall, correlation between electricity consumption for ventilation fans and story drift of story 3 in Y-direction is 0.99. Also, correlation between total electricity consumption and story drift of story 4 in Y-direction is 0.99. For changes in other walls, the highest positive correlation is observed between electricity consumption for space cooling and story drift of story 4 in Y-direction (0.97). It indicates that they significantly reinforce each other.

- In contrast, some indicators are highly negatively correlated. For example: for changes in the south wall, correlation between electricity consumption for hot water and story drift in X-direction for story 2 is -0.99. Similarly, correlation between electricity consumption between heat pump supply and story drift in $X$ direction for story 1 is also -0.99. For changes in other walls, correlation between electricity consumption between heat pump supply and story drift in Y-direction for story 2 is -0.54. These correlation values indicate that they significantly undermine each other.

- Some indicators have highly positive and highly negative correlation. Such indicators should be analyzed with significant details by designers and associated stakeholders while designing an infrastructure. As they can significantly enhance 
or weaken each other, their correlation will have critical impact in deciding the final design parameters of an infrastructure.

- With additional openings in walls of opposite directions (i.e. north over south or East over West), the effects on sustainability and resilience indicators did not follow any consistent pattern based on combined assessments. This indicates the necessity for more detailed assessments on the directional effects to unify these two concepts.

- For each case result, the highest story drift in X-direction is observed for story 4; however, higher drifts in Y-direction were observed for story 3 rather than story 4. Due to a recent increase in frequency and magnitude of natural disasters, and the need to increase capacity of infrastructures to deal with such disasters, the concept of resilience is becoming more important than ever before. Similarly, rapid consumption of natural resources is one of the main reasons why the sustainability as a concept is getting a lot of attention from the world of researchers. As such, both concepts are equally important and the analytical framework presented in this study can support planners, designers, and builders among others to identify more feasible alternatives, ensuring both sustainability and resilience of a given infrastructure system. Such an approach is particularly relevant for recent efforts in the study of interdependent systems.

\subsection{Thesis Contributions}

The quantification and unification of sustainability and resilience indicators will assist associated stakeholders to make justifiable decisions regarding design and selection of various components of an infrastructure. This approach will help in analyzing and finalizing various design parameters with calculated risk based on quantitative analysis of 
both sustainability and resilience indicators. The novel methodology of assessment used in this study can be used for various types of civil infrastructure systems with appropriate modifications. It can also help future researchers to analyze such unification of sustainability and resilience from a new perspective.

\subsection{Limitations and Future Directions}

The variable used in this study is the opening of the building, and all other factors are fixed. However, in a real case scenario, this might not hold true because changing an opening might affect other parameters of the building. For effective assessment of sustainability, future research should consider other factors affecting sustainability of a building, such as water efficiency, waste management, social aspects etc., which are not considered in this study. In addition, factors including function and orientation of the building can be considered for sustainability assessment. The weather data for sustainability assessment can be made more realistic with accurate data particular to the location being considered. For resilience assessment, other types of hazards can be considered, as this study only considered Earthquake as the main hazard. In addition, simplified approach for optimization and regression were adopted for this study, which can be done in a more detailed manner by future studies.

Implementing a similar approach for reinforced concrete frame structures should be explored in the future. Effects on sustainability and resilience indicators due to variation in other components of the building should also be analyzed in future studies. For example: by varying type of materials used for construction, future research can observe its effects on sustainability and resilience indicators, not within the scope of this research. In addition, 
future studies can explore more on finding the intermediate values of both sustainability and resilience indicators to find a more accurate value of tipping point. Future research can also explore any possible optimality concept (such as pareto optimality) to determine exact optimal value of different parameters. Using concepts like pareto optimality, stakeholders can finalize various design parameters that will provide best case scenario (or results) with regard to both sustainability and resilience indicators.

Future research should provide more concentrated efforts to identify: (i) additional sustainability and resilience indicators that can help better unify the two concepts; (ii) onefits-all or more generalized frameworks that can efficiently integrate sustainability and resilience of infrastructure systems; (iii) thresholds or tipping points above or beyond which they reinforce or undermine each other; (iv) indicators that are more dependent or independent of phases in the life cycle i.e. planning, design, construction, operation and maintenance; (v) relative importance of such indicators; (vi) perspective of wall to window ratio instead of percentage of opening. Future research should also explore more on directional effects as well as the effects on different stories of the building due to the changes in opening. A good starting point would be to revisit the current standards of existing building codes and introduce rating systems such as Leadership in Energy and Environmental Design (LEED) certifications and American Society of Civil Engineers (ASCE) Infrastructure Report Card. 


\section{REFERENCES}

1. Griggs, D., et al., Policy: Sustainable development goals for people and planet. Nature, 2013. 495(7441): p. 305.

2. Brundtland, G.H., Our common future: Brundtland-report. 1987: Oxford University Press, Oxford.

3. Hasik, V., et al., Investigation of the sustainability and resilience characteristics of buildings including existing and potential assessment metrics, in AEI 2017. 2017. p. 1019-1033.

4. Klein, R.J., R.J. Nicholls, and F. Thomalla, Resilience to natural hazards: How useful is this concept? Global environmental change part B: environmental hazards, 2003. 5(1): p. 35-45.

5. Marjaba, G. and S. Chidiac, Sustainability and resiliency metrics for buildingsCritical review. Building and environment, 2016. 101: p. 116-125.

6. Bocchini, P., et al., Resilience and sustainability of civil infrastructure: Toward a unified approach. Journal of Infrastructure Systems, 2013. 20(2): p. 04014004.

7. Roostaie, S., N. Nawari, and C. Kibert, Sustainability and resilience: A review of definitions, relationships, and their integration into a combined building assessment framework. Building and Environment, 2019.

8. Bosher, L., et al., Realising a resilient and sustainable built environment: towards a strategic agenda for the United Kingdom. Disasters, 2007. 31(3): p. 236-255.

9. Cremers, J., in Openings in buildings. 2016, Detail. p. 6.

10. Taucer, F., Unreinforced Masonry Buildings, in Encyclopedia of Natural Hazards, P.T. Bobrowsky, Editor. 2013, Springer Netherlands: Dordrecht. p. 1062-1063.

11. Elkington, J., The triple bottom line sustainability's accountants. Retrieved January, 1997. 23: p. 2003.

12. Lew, A.A., et al., Community sustainability and resilience: Similarities, differences and indicators. Tourism Geographies, 2016. 18(1): p. 18-27.

13. Seager, T.P., The sustainability spectrum and the sciences of sustainability. Business Strategy and the Environment, 2008. 17(7): p. 444-453.

14. Ruuska, A. and T. Häkkinen, Material efficiency of building construction. Buildings, 2014. 4(3): p. 266-294. 
15. Junnila, S. and A. Horvath, Life-cycle environmental effects of an office building. Journal of Infrastructure Systems, 2003. 9(4): p. 157-166.

16. Scheuer, C., G.A. Keoleian, and P. Reppe, Life cycle energy and environmental performance of a new university building: modeling challenges and design implications. Energy and buildings, 2003. 35(10): p. 1049-1064.

17. Ochoa, L., C. Hendrickson, and H.S. Matthews, Economic input-output life-cycle assessment of US residential buildings. Journal of Infrastructure Systems, 2002. 8(4): p. 132-138.

18. Stirling, A., The appraisal of sustainability: some problems and possible responses. Local Environment, 1999. 4(2): p. 111-135.

19. Linkov, I., et al., Changing the resilience paradigm. Nature Climate Change, 2014. 4(6): p. 407.

20. Folke, C. and L. Gunderson, Resilience and global sustainability. Ecology and Society, 2010. 15(4).

21. Manyena, B., et al., Disaster resilience: a bounce back or bounce forward ability? Local Environment: The International Journal of Justice and Sustainability, 2011. 16(5): p. 417-424.

22. Marchese, D., et al., Resilience and sustainability: Similarities and differences in environmental management applications. Science of the Total Environment, 2018. 613: p. 1275-1283.

23. Redman, C., Should sustainability and resilience be combined or remain distinct pursuits? Ecology and Society, 2014. 19(2).

24. Council, N.R., Disaster resilience: A national imperative. 2012, Washington, DC: The National Academies Press.

25. Kneer, E. and L. Maclise. Consideration of building performance in sustainable design: a structural engineer's role. in Proceedings of the 2008 SEAOC (Structural Engineers Association of California) Convention, Hawaii, september. 2008.

26. Leichenko, R., Climate change and urban resilience. Current opinion in environmental sustainability, 2011. 3(3): p. 164-168.

27. Stewart, M.G. and X. Deng, Climate impact risks and climate adaptation engineering for built infrastructure. ASCE-ASME Journal of Risk and Uncertainty in Engineering Systems, Part A: Civil Engineering, 2014. 1(1): p. 04014001.

28. Jha, A.K., T.W. Miner, and Z. Stanton-Geddes, Building urban resilience: principles, tools, and practice. 2013: The World Bank. 
29. Bruneau, M., et al., A framework to quantitatively assess and enhance the seismic resilience of communities. Earthquake spectra, 2003. 19(4): p. 733-752.

30. Adjetey-Bahun, K., et al., A model to quantify the resilience of mass railway transportation systems. Reliability Engineering \& System Safety, 2016. 153: p. 114.

31. Panteli, M., et al., Metrics and quantification of operational and infrastructure resilience in power systems. IEEE Transactions on Power Systems, 2017. 32(6): p. 4732-4742.

32. Tamvakis, P. and Y. Xenidis, Comparative evaluation of resilience quantification methods for infrastructure systems. Procedia-Social and Behavioral Sciences, 2013. 74: p. 339-348.

33. Franchin, P. and F. Cavalieri, Probabilistic assessment of civil infrastructure resilience to earthquakes. Computer-Aided Civil and Infrastructure Engineering, 2015. 30(7): p. 583-600.

34. Moser, S., et al., The turbulent world of resilience: interpretations and themes for transdisciplinary dialogue. Climatic change, 2019. 153(1-2): p. 21-40.

35. Cutter, S.L., et al., A place-based model for understanding community resilience to natural disasters. Global environmental change, 2008. 18(4): p. 598-606.

36. Zhao, D., A.P. McCoy, and J. Smoke, Resilient built environment: New framework for assessing the residential construction market. Journal of Architectural Engineering, 2015. 21(4): p. B4015004.

37. Zolli, A. and A.M. Healy, Resilience: Why things bounce back. 2012: Hachette UK.

38. Champagne, C.L. and C.B. Aktas, Assessing the resilience of LEED certified green buildings. Procedia Engineering, 2016. 145: p. 380-387.

39. Chopra, S.S., et al., A network-based framework for assessing infrastructure resilience: a case study of the London metro system. Journal of The Royal Society Interface, 2016. 13(118): p. 20160113.

40. Folke, C., Resilience: The emergence of a perspective for social-ecological systems analyses. Global environmental change, 2006. 16(3): p. 253-267.

41. Xu, L., D. Marinova, and X. Guo, Resilience thinking: a renewed system approach for sustainability science. Sustainability Science, 2015. 10(1): p. 123-138.

42. Phillips, R., et al., Do resilient and sustainable design strategies conflict in commercial buildings? A critical analysis of existing resilient building frameworks and their sustainability implications. Energy and Buildings, 2017. 146: p. 295-311. 
43. Bozza, A., D. Asprone, and G. Manfredi, Developing an integrated framework to quantify resilience of urban systems against disasters. Natural Hazards, 2015. 78(3): p. 1729-1748.

44. Lizarralde, G., et al., Sustainability and resilience in the built environment: The challenges of establishing a turquoise agenda in the UK. Sustainable Cities and Society, 2015. 15: p. 96-104.

45. Ugwu, O. and T.C. Haupt, Key performance indicators and assessment methods for infrastructure sustainability - a South African construction industry perspective. Building and Environment, 2007. 42(2): p. 665-680.

46. Ariaratnam, S.T., et al., Quantification of sustainability index for underground utility infrastructure projects. Journal of construction engineering and management, 2013. 139(12): p. A4013002.

47. Rose, A., Economic resilience to natural and man-made disasters: Multidisciplinary origins and contextual dimensions. Environmental Hazards, 2007. 7(4): p. 383-398.

48. Berkes, F., Understanding uncertainty and reducing vulnerability: lessons from resilience thinking. Natural hazards, 2007. 41(2): p. 283-295.

49. Achour, N., et al., Integration of resilience and sustainability: from theory to application. International Journal of Disaster Resilience in the Built Environment, 2015. 6(3): p. 347-362.

50. Yüksel, Ç.Y. and H. Sözer, Energy Efficiency for Hot-Humid Climate Based On Openings and Roof Type, Adana Case. Energy, 2019. 4(4).

51. Lai, C.-M. and Y.-H. Wang, Energy-saving potential of building envelope designs in residential houses in Taiwan. Energies, 2011. 4(11): p. 2061-2076.

52. Parisi, F. and N. Augenti, Seismic capacity of irregular unreinforced masonry walls with openings. Earthquake Engineering \& Structural Dynamics, 2013. 42(1): p. 101-121.

53. Yi, T., et al., Lateral load tests on a two-story unreinforced masonry building. Journal of Structural Engineering, 2006. 132(5): p. 643-652. 